\title{
Mechanical properties of ambient cured high-strength plain and hybrid fiber reinforced geopolymer composites from triaxial compressive tests
}

\author{
Musaad Zaheer Nazir Khan ${ }^{1,2}$, Yifei Hao ${ }^{3 *}$, Hong Hao ${ }^{1,4 *}$, Faiz Uddin Ahmed Shaikh ${ }^{1} \&$ Kewei Liu ${ }^{5}$ \\ ${ }^{1}$ Centre for Infrastructural Monitoring \& Protection, Curtin University, Bentley, Perth, Australia \\ ${ }^{2}$ School of Civil \& Environmental Engineering, National University of Sciences \& Technology, Sector H-12, Islamabad, Pakistan \\ ${ }^{3}$ Key Laboratory of Coast Civil Structure Safety (Tianjin University), Ministry of Education, Tianjin 300350, China \\ ${ }^{4}$ School of Civil Engineering, Guangzhou University, Guangzhou 510006, China \\ ${ }^{5}$ School of Resources and Safety Engineering, Central South University, Changsha, China
}

\section{Abstract}

Geopolymer binders have evolved as a promising alternative to ordinary Portland cement (OPC) in concrete over the last few decades. However, many aspects of their mechanical behaviour such as their performance under multiaxial stress conditions are still unknown, which are of primary importance for their structural application. In this paper, the triaxial compressive behaviour of newly developed ambient-cured high-strength geopolymer (HSG) mortar, and fiber reinforced geopolymer composites (FRGC) is studied. A series of $\varnothing 50 \times 100 \mathrm{~mm}$ cylindrical samples were prepared using low-calcium fly ash and ground granulated blast furnace slag, while hybrid steel-polyethylene fiber reinforcement with fiber volume fraction of $2 \%$ was used to reinforce the brittle geopolymer matrix. Standard triaxial tests with fifteen different levels of confining pressures [ $\left(\sigma_{3}\right)$; ranging between 0 and $100 \mathrm{MPa}$ ] were employed to comprehensively investigate the triaxial stress-strain characteristics of synthesized materials from low to high range of confining pressures. According to test results, the unreinforced HSG samples exhibited linear elastic stress-strain behaviour under uniaxial stress condition and showed catastrophic brittle failure. Instead, the samples tested under confinement showed pseudo-ductile behaviour. On the other hand, the inclusion of hybrid-fiber reinforcement has meaningfully helped to improve the ductility of HSG matrix. The peak axial stress and the corresponding axial strain was found to increase with the increase of confining pressure, although the influence of active lateral confinement was more pronounced on the triaxial strength of HSG samples. The two most commonly used failure criterions for OPC concrete, i.e., Power-law and Willam-Warnke failure criterion were used to develop the empirical relations to predict the peak axial stress as a function of confining pressure for the studied materials. The proposed relationships can be used for the calibration of existing concrete material models. The obtained test results were also compared with the existing triaxial compression test data on high strength cement based concretes and composites in the literature to highlight the differences between geopolymers and OPC concrete.

Keywords: Geopolymer, Fiber reinforced geopolymer composites, Confining pressure, Failure criterion, Triaxial compression, Compressive strength, Mechanical Properties

"Corresponding author, Emails: hong.hao@curtin.edu.au (Hong Hao); hao.yifei@tju.edu.cn (Yifei Hao) 


\section{Introduction}

2 With an ever growing demand for using sustainable alternatives to ordinary Portland cement (OPC),

3 the modern construction materials have seen a new cementless binder in the form of "Geopolymer" [1].

4 The specific advantages of using by-product source materials [2], high early-age strength [3], improved

5 fire resistance [4], and reduced carbon dioxide $\left(\mathrm{CO}_{2}\right)$ emissions [5] have driven an increased research

6 interest in these new alkali-activated cementitious materials (AACMs). Previous studies on geopolymer

7 materials have identified numerous factors, such as, the nature of silico-aluminous materials [6], types

8 of alkali-activators [7], mixing sequences [8], and curing conditions [9] that could significantly

9 influence their mechanical properties. Some other investigators focused on improving their structural

10 resistance, toughness, and flexure tensile strength by introducing epoxy-resins [10] and a range of fiber

11 types in different geopolymer formulations [11].

12 However, for practical use of geopolymers in civil engineering applications, the availability of

13 constitutive relationships which can empirically predict their behaviour under combined stress states is

14 still a grey area for these novel binders. Generally, the compressive strength of concrete is the

15 fundamental property commonly used in the design of reinforced concrete structures. However, in the majority of the cases, the failure of concrete in a structure occurs under complex stress states [12].

17 Besides, it is well established that owing to an inherent microstructural variation, almost all engineering materials deform distinctively. Thus it is the information on failure mechanism under complex loading conditions that form the basis of developing constitutive models or failure criteria for them [13]. A

20 thorough understanding of the behaviour of geopolymer binders under multiaxial stress states is

21 necessary. In this regard, the stress-strain behaviour of the materials is usually investigated under a 22 series of lateral confinements or more commonly referred to as "triaxial stress" conditions. 
1 In the past, starting from as early as 1929, Richart et al. [14] made the pioneer investigation to

2 understand the triaxial behaviour of concrete. Many researchers have studied the behaviour of ordinary

3 and cement affluent, high and ultra-high strength fiber reinforced concretes (NSC, HSC or UHSFRC)

4 under multiaxial compression. Various stress-strain models have been proposed, which can adequately

5 regenerate the load-deformation behaviour of concrete under confinement, e.g., for the concrete

6 material used in infilled steel tubular columns or concrete columns confined with high tensile strength

7 fiber-reinforced polymer fabric and steel reinforcements, etc. [15]. Other researchers, e.g. [16-22], used

8 the triaxial compression test results to predict the generalized strength enhancement, material

9 deformation, residual strength capacity, and volumetric expansion for OPC concrete. However, some

10 apparent differences in these studies are related to the type of concrete materials, including NSC or

11 HSC, the presence of fibers, sample sizes, and the range of low or high confining pressures used during

12 the tests.

13 On the other hand, the existing database on the triaxial compressive behaviour of geopolymer mortar,

14 concrete, and composite materials is trivial. The existing studies only provide preliminary information

15 on the triaxial stress-strain behaviour of geopolymer pastes. For example, amongst the very few,

16 Giasuddin et al. [23] investigated the stress-strain characteristics of two differently graded geopolymer

17 pastes, (i.e. high $(85 \mathrm{MPa})$ and low $(28 \mathrm{MPa})$ under a range of low confining pressures, i.e. $\sigma_{3} / f^{\prime}{ }_{c} \leq$

180.40 , where $\sigma_{3}$ is the confining pressure, and $f^{\prime}{ }_{c}$ denotes the compressive strength. Based on their test

19 data, linear strength constitutive model as per Mohr coulomb's failure criteria and modified parabolic

20 relation of Xiao et al. [24] with slightly different material constants was proposed. They concluded that

21 the trend of strength enhancement of geopolymer paste is similar to OPC concrete under confinement.

22 However, previous studies show that the constitutive relationships proposed for low levels of

23 confinement ratios $\left(\sigma_{3} / f^{\prime}{ }_{c}\right)$ may lead to an erroneous prediction of the material behaviour at higher levels 
1 of confinement [25]. Similarly, for critical axial strain corresponding to peak axial stress, they also

2 modified Xiao et al. [24] parabolic equation proposed for axial deformation. The constant in the

3 constitutive relation for geopolymer paste was found to be significantly lower than that of NSC or HSC.

4 The fitted curves suggested increased stiffness in geopolymer material as compared to OPC concrete.

5 Given that the conclusion may be valid for geopolymer binders due to their ceramics-like nature,

6 however, it is believed that the finding may also stem from the difference in the employed load paths.

7 In Xiao et al.'s tests [24], the longitudinal axial stress was only applied after the confining pressure

8 reached a specified target value (i.e., proportional load path) instead of a standard loading path used by

9 Giasuddin et al. [23]. The slopes of ascending portions of the stress-strain curves tend to be lower than

10 that of the samples tested in uniaxial compression in the latter case and could be otherwise as reported

11 in other investigations $[21,26]$.

12 In another investigation [27], metakaolin based geopolymer mixtures containing varying silicon

13 dioxide to sodium oxide $\left(\mathrm{SiO}_{2} / \mathrm{Na}_{2} \mathrm{O}\right)$ molar ratios were tested under uniaxial and triaxial compressive

14 stress states. The primary goal of this research was to identify the influence of various $\mathrm{SiO}_{2} / \mathrm{Na}_{2} \mathrm{O}$ molar

15 oxide ratios on the microstructure development of geopolymers and their modification under a set of

16 low confining pressures. The microstructure of geopolymer intrinsically relied on the level of

17 polymerization and the formation of $\mathrm{Q}^{4}(\mathrm{nAl})$ network within the binding gels which control their

18 failure modes under confinement. The research concludes that a well-formed geopolymer material fails

19 in a brittle manner in uniaxial compression, while with an increase in the confining stress the failure

20 mode changes from brittle to ductile.

21 Very recently, with an objective of using geopolymer cement in carbon storage sequestration wells,

22 Nasvi et al. [28] carried out a numerical study to investigate the influence of various confining pressures

23 (from $5 \mathrm{MPa}$ to $25 \mathrm{MPa}$ ) on geopolymer materials prepared under different curing temperatures (i.e., 
1 from $23^{\circ} \mathrm{C}$ to $80^{\circ} \mathrm{C}$ ). According to test results, at a given confining pressure, the deviatoric strength

2 increased for geopolymer binders synthesized up to a temperature of $60^{\circ} \mathrm{C}$ beyond which the increase

3 in deviatoric strength reduced by $15 \%$ for all levels of curing temperatures. However, the geopolymer

4 paste synthesized at $80^{\circ} \mathrm{C}$ had lower uniaxial compressive strength in comparison to the samples cured

5 at $60^{\circ} \mathrm{C}$ or more moderate temperatures. As such, the stress-strain curve used for the calibration of the

6 numerical model had lower peak axial stress value. Hence, a noticeable reduction in the deviatoric

7 strength increase was not a surprise. Besides, for a given curing temperature, the increase in deviatoric

8 strength at lower confinement levels (5 $\mathrm{MPa}$ to $15 \mathrm{MPa}$ ) was more as compared to higher lateral

9 confinements (20 MPa and $25 \mathrm{MPa})$. Although, as reasonable as this finding may be, the exact reason

10 for the observed mechanical behaviour is unknown.

11 As apparent from the technical review, for the broader use of geopolymer composites in the

12 construction of structures that could be potentially at risk of experiencing moderate to high levels of

13 confinement, no research data are available in the literature. In the same way, no literature exists for

14 the case where fibers are present in geopolymer mixtures to improve their ductility and the cracking is

15 restrained from other sources such as confinement apart from the fiber reinforcement. Also, as

16 highlighted above, two out of three investigations utilized heat curing method for the synthesis of

17 geopolymer which could be a significant limitation for the proposed mixtures in a more generalized

18 cast-in-situ situation. To the best knowledge of the authors, no study has been carried out in the past

19 which comprehensively investigates the triaxial compressive behaviour of high-strength ambient cured

20 geopolymer mortar and fiber-reinforced composite materials under a high level of confining stress.

21 Therefore, the current research attempts to bridge these gaps in the literature and acquires test data

22 concerning the behaviour of ambient cured high-performance geopolymer mortar and fiber reinforced

23 geopolymer composites under uniaxial and triaxial compressive stress states. The experimental 
1 program comprises of testing two types of geopolymer mixtures, i.e., high-strength geopolymer mortar

2 and fiber reinforced geopolymer composite under uniaxial and triaxial compression stress states over a

3 range of confinement ratios ranging from 0.02 to 1.00 . Based on the results presented in this paper,

4 empirical relationships are proposed to predict the peak axial strength and critical axial strain at peak

5 stress as a function of the confining pressure for the studied materials. Similarly, the uniaxial and

6 triaxial stress-strain curves of the two types of materials are compared and discussed alongside their

7 failure patterns. Finally, the two most common failure criteria (i.e., Power-law and Willam-Warnke)

8 are calibrated with the results of HSG and FRGC for failure envelopes and compared to those of high

9 strength concrete and fiber reinforced cement composites (FRCCs) available in the literature.

\section{2. Experimental Approach}

\subsection{Mixture proportions}

12 This research utilizes two types of geopolymer mixtures, i.e., high strength geopolymer mortar and fiber reinforced geopolymer composite (from now on referred as "HSG" and "FRGC" respectively).

14 Table 1 presents the mixture proportions for HSG and FRGC samples. As such, these proportions are adopted from preceding studies, where they were found to have desirable workability, strength properties, and showed uniform fiber distribution [6, 29]. The FRGC mixture contained a hybrid-fiber

17 blend of steel and high-strength polyethylene (HSPE) fibers at a predetermined ratio. No expensive raw materials including the high content of fine quartz sand or silica fume were used in these mixtures, while, the rationality of using a hybrid-fiber mix has been explained elsewhere [30]. Moreover, for the use of FRGC as a structural material, it is necessary to include sufficient volume fraction of fibers such

21 that they can play a significant role in improving the mechanical properties of HSG. Therefore, we

22 chose a total fiber volume fraction of $2 \%$ for the active involvement of fibers in enhancing the ductility 23 of HSG matrix. 
1 Table 1 Mix proportions of HSG and FRGC

\begin{tabular}{|c|c|c|c|}
\hline \multicolumn{2}{|l|}{ Mix type / Mix ingredient } & \multirow{2}{*}{ Material details } & \multirow{2}{*}{$\begin{array}{l}\text { Quantity } \\
\left(\mathrm{kg} / \mathrm{m}^{3}\right)\end{array}$} \\
\hline HSG & FRGC & & \\
\hline Fly ash & Fly ash & ASTM - Class F & 412 \\
\hline Slag & Slag & Construction grade & 276 \\
\hline Fine aggregates & Fine aggregates & Silica sand $(0-1.18 \mathrm{~mm})$ & 1100 \\
\hline $\mathrm{Na}_{2} \mathrm{SiO}_{3}{ }^{\mathrm{a}}$ & $\mathrm{Na}_{2} \mathrm{SiO}_{3}$ & D-grade & 294 \\
\hline $12 \mathrm{M} \mathrm{NaOH}^{\mathrm{b}}$ & $12 \mathrm{M} \mathrm{NaOH}$ & $99 \%$ pure $\mathrm{NaOH}$ beads & 118 \\
\hline \multirow{3}{*}{-} & \multirow{2}{*}{ Steel fibers } & Hooked-end & $0.80^{\mathrm{c}}$ \\
\hline & & Spiral steel & $0.80^{\mathrm{c}}$ \\
\hline & Synthetic fibers & HSPE & $0.40^{\mathrm{c}}$ \\
\hline Water-binder ratio & - & $0.28^{\mathrm{d}}$ & $0.28^{\mathrm{d}}$ \\
\hline \multirow{4}{*}{ Critical oxide molar ratios } & $\mathrm{Na}_{2} \mathrm{O} / \mathrm{SiO}_{2}$ & 0.21 & 0.21 \\
\hline & $\mathrm{Na}_{2} \mathrm{O} / \mathrm{Al}_{2} \mathrm{O}_{3}$ & 0.95 & 0.95 \\
\hline & $\mathrm{Si} / \mathrm{Al}$ & 2.30 & 2.30 \\
\hline & $\mathrm{H}_{2} \mathrm{O} / \mathrm{Na}_{2} \mathrm{O}$ & 10.49 & 10.49 \\
\hline
\end{tabular}

$2 \quad \bar{a}$ D-grade Sodium silicate; ${ }^{b} 99 \%$ pure Sodium hydroxide pellets; ${ }^{c}$ Fibers are included by volume percentage $\left(V_{f} \%\right)$;

$3{ }^{d}$ Numerical fraction

$4 \quad 2.2$ Material composition and fiber properties

5 The low-calcium fly ash (fly ash), equivalent to ASTM Class-F [31] with a specific surface area of

$63400 \mathrm{~cm}^{2} / \mathrm{g}$ and median particle size of $9.7 \mu \mathrm{m}$ was sourced from Gladstone Power Station in

7 Queensland, Australia. Ground-granulated blast furnace slag (slag) having a specific surface area of

$8 \quad 3700 \mathrm{~cm}^{2} / \mathrm{g}$ and median particle size of $11.5 \mu \mathrm{m}$ was used as an additive to the fly ash. Fig. 1 shows the

9 X-ray diffraction (XRD) patterns and particle size distributions of the solid precursors, while their

10 chemical properties and loss on ignition (LOI) established via X-ray fluorescence (XRF) analysis are

11 included in Table 2. 


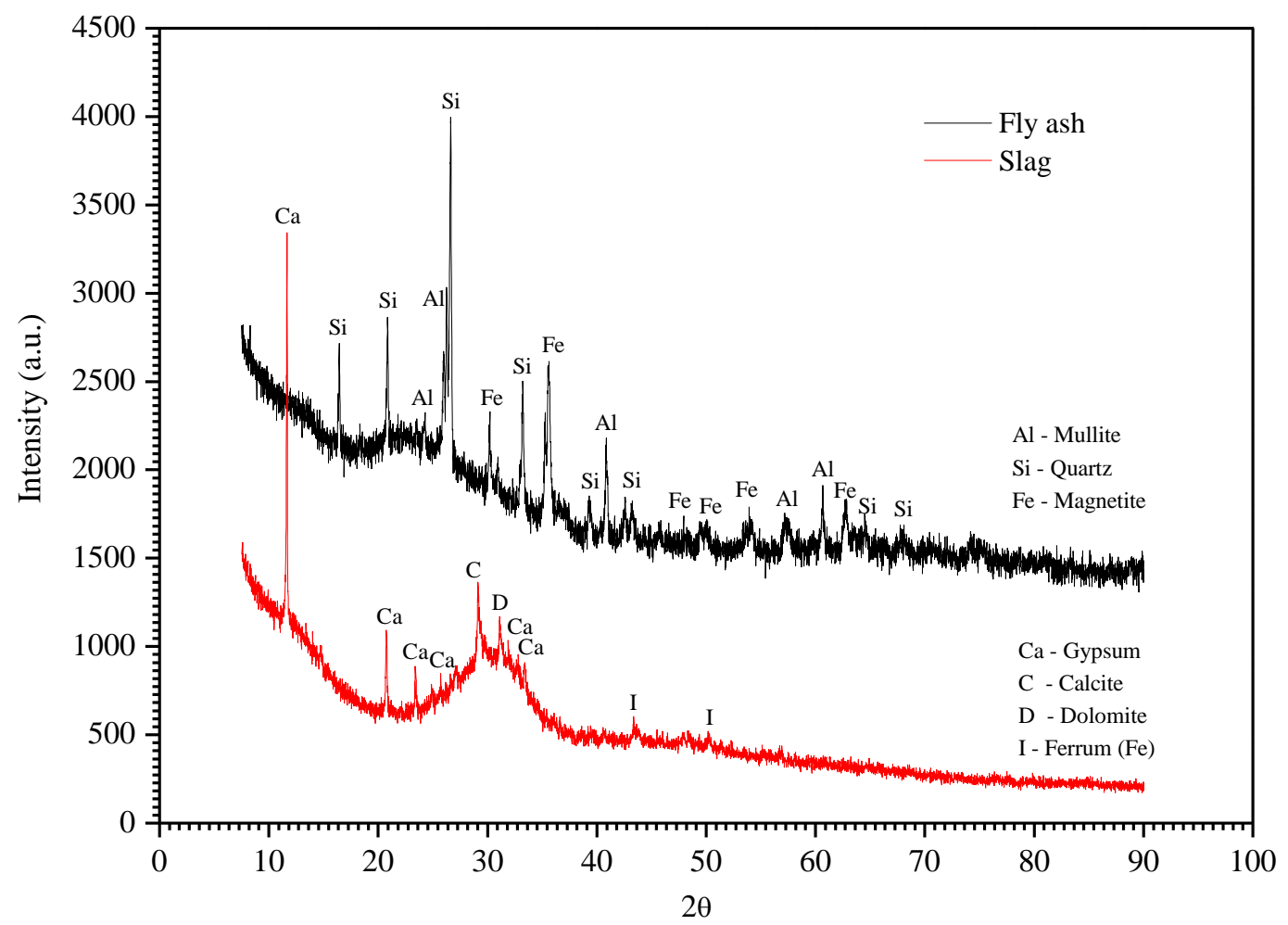

(a)

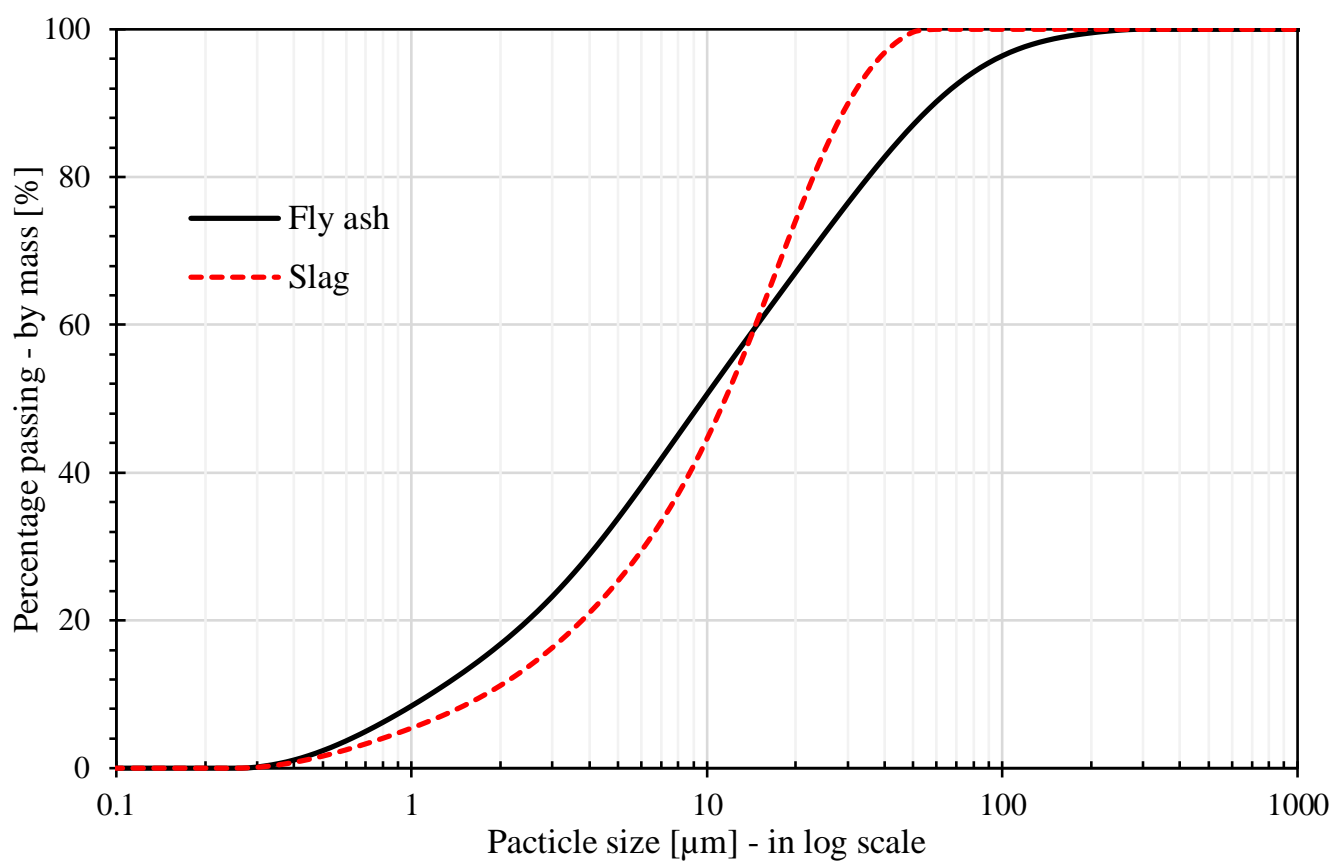

(b)

Fig. 1. (a) XRD $2 \theta\left(^{\circ}\right) \mathrm{Cu}, \mathrm{K}-\alpha$ patterns and (b) particle size distributions of fly ash and slag 
1 The unprocessed pozzolanic waste contains both the amorphous and crystalline components (see Fig.

2 1), however, during activation only the amorphous contents react while the crystalline components act

3 as a filler. It has been used as an advantage in this study by incorporating local silica sand having a

4 fineness modulus of 2.77 and specific gravity of 2.65 in the geopolymer mixes. However, the fine 5 aggregates were prepared in saturated surface dry (SSD) condition before being used for the preparation 6 of mixtures as per ASTM C128-15 [32]. The alkaline-activator was a blended mixture of 12M sodium

7 hydroxide $(\mathrm{NaOH})$ and $\mathrm{D}$-grade sodium silicate $\left(\mathrm{Na}_{2} \mathrm{SiO}_{3}\right)$ solution, supplied by Chem Supply Pty Ltd 8 and PQ-Australia Pty Ltd [6]. The 99\% pure $\mathrm{NaOH}$ beads were diluted in tap water to achieve a mass 9 ratio of 2.50 between $\mathrm{Na}_{2} \mathrm{SiO}_{3} / \mathrm{NaOH}$ and, Table 2 reflects their final chemical compositions. 
1 Table 2 Chemical composition of low-calcium fly ash, slag and alkali-activators

\begin{tabular}{lllll}
\hline Chemical analyses $(\%)$ & Slag & Fly ash & $\mathrm{NaOH}$ & $\mathrm{Na}_{2} \mathrm{SiO}_{3}$ \\
\hline Calcium oxide $(\mathrm{CaO})$ & 41.22 & 4.30 & - & - \\
Silicon dioxide $\left(\mathrm{SiO}_{2}\right)$ & 32.45 & 51.11 & - & 29.40 \\
Aluminum oxide $\left(\mathrm{Al}_{2} \mathrm{O}_{3}\right)$ & 13.56 & 25.56 & - & - \\
Magnesium oxide $(\mathrm{MgO})$ & 5.10 & 1.45 & - & - \\
Sulfur trioxide $\left(\mathrm{SO}_{3}\right)$ & 3.20 & 0.24 & - & - \\
Ferric oxide $\left(\mathrm{Fe}_{2} \mathrm{O}_{3}\right)$ & 0.85 & 12.48 & - & - \\
Potassium oxide $\left(\mathrm{K}_{2} \mathrm{O}\right)$ & 0.35 & 0.70 & - & 14.70 \\
Sodium oxide $\left(\mathrm{Na}_{2} \mathrm{O}\right)$ & 0.27 & 0.77 & 28.05 & - \\
Manganese oxide $(\mathrm{MnO})$ & 0.25 & 0.15 & - & - \\
Phosphorus pentoxide $\left(\mathrm{P}_{2} \mathrm{O}_{5}\right)$ & 0.03 & 0.89 & - & - \\
Others & 1.61 & 1.78 & - & - \\
Loss on ignition $(\mathrm{LOI})$ & 1.11 & 0.57 & - & 55.90 \\
Water $\left(\mathrm{H}_{2} \mathrm{O}\right)$ & - & - & 71.95 & \\
\hline
\end{tabular}

2

3 The physical appearance and the properties of fibers used in the investigation are presented in Fig. 2

4 and Table 3, respectively. The hooked-end and spiral steel fibers were purchased from two different

5 suppliers based in China, while Dyneema Group, Toyobo Corporation Ltd Japan supplied the HSPE 6 fibers.

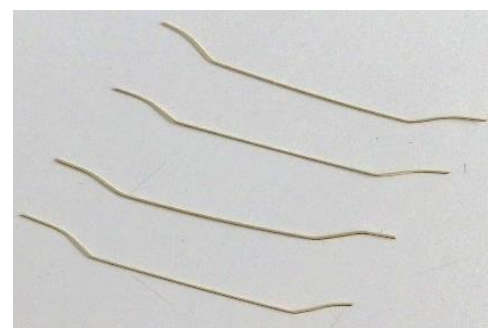

(a)

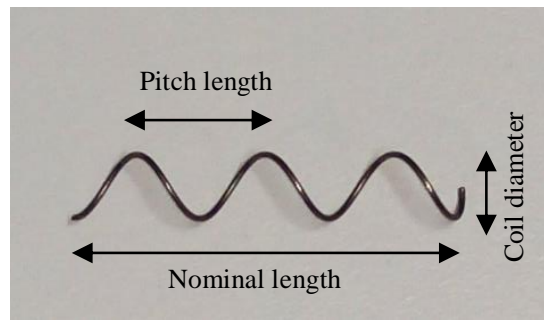

(b)

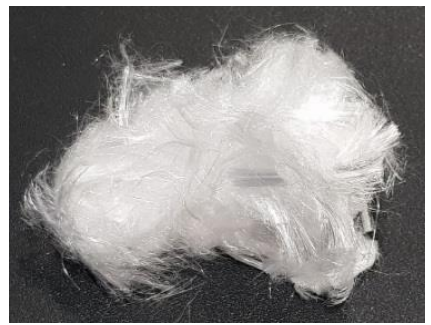

(c)

Fig. 2. Physical appearance of (a) Hooked-end steel (b) Spiral steel (c) HSPE fibers 
1 Table 3 Physical and mechanical properties of fibers

\begin{tabular}{llll}
\hline Fiber type / Property & $\begin{array}{l}\text { Hooked-end steel } \\
(\text { GSF-025) }\end{array}$ & Spiral steel & $\begin{array}{l}\text { High strength polyethylene } \\
\text { (HSPE-SK71) }\end{array}$ \\
\hline Wire diameter $(\mathrm{mm})$ & 0.30 & 0.55 & 0.012 \\
Nominal length $(\mathrm{mm})$ & 25 & 25 & 12 \\
Coil diameter $(\mathrm{mm})$ & - & 6 & - \\
Pitch length $(\mathrm{mm})$ & - & 10 & - \\
Aspect ratio $(\mathrm{l} / \mathrm{d})$ & 85 & 45 & 1000 \\
Nominal tensile strength $(\mathrm{MPa})$ & 2500 & 2000 & 3500 \\
Elongation capacity $(\%)$ & $<1.00$ & $<1.00$ & 3.30 \\
Modulus of elasticity $(\mathrm{GPa})$ & 200 & 200 & 123 \\
Density $\left(\mathrm{gm} / \mathrm{cm}^{3}\right)$ & 7.80 & 7.80 & 0.97 \\
\hline
\end{tabular}

2

2.3 Mixing process, casting, curing, and sample design

After preparing the ingredients mentioned in Table 1, the mixing process was carried out in a 70L large

5 size pan mixer. The mixing speed was controlled rigorously at 50 revolutions per minute (RPM) to ensure the uniform distribution of ingredients. Following steps were then taken to prepare the mixtures:

1. At first, all the dry constituents including fly ash, fine aggregates, and slag were mixed for 4 minutes. The dry-mixed ingredients were checked for lumps formation as small particles tend mortar was measured to make sure that it is within a desirable range for the next process.

3. At this stage, the freshly prepared HSG mixture was poured into $\varnothing 50 \mathrm{~mm} \times 110 \mathrm{~mm}$ cylindrical PVC plastic molds. The molds were filled in three layers, while a continuous external vibration process was used to remove the entrapped air bubbles. 
4. For FRGC, the measurement of workability was followed by the addition of hooked-end and spiral steel fibers through a constant sieve shaking process while continuously mixing the ingredients during the process. Finally, to provide the uniform dispersion of HSPE fibers, they were separated loosely and included in small portions via hand into the wet mixture. The total mixing time of FRGC mixture was around 20-25 mins. According to ASTM C1437-13 [33], the measured flow diameters of geopolymer mortar and FRGC mixes were $145 \mathrm{~mm}$ and $65 \mathrm{~mm}$, respectively.

Unlike HSG mix, the freshly prepared FRGC mixture was poured into rectangular slab timber molds having a dimension of $110 \mathrm{~mm} \times 200 \mathrm{~mm} \times 1000 \mathrm{~mm}$ and compacted via an external vibrating table. It was mainly done to assure the random distribution and orientation of fibers as well as to represent the typical volumetric element size as compared to the $\varnothing 50 \mathrm{~mm} \times 110 \mathrm{~mm}$ cylindrical molds. The inner surfaces were lined with oil to minimize the friction between the poured material and the timber material. The cast samples and slabs were cured at a temperature of $23 \pm 2^{\circ} \mathrm{C}$ for the next $24 \mathrm{hrs}$. Later, the hardened specimens were demolded and stored in a standard environment $\left(23 \pm 2^{\circ} \mathrm{C}\right.$ and relative

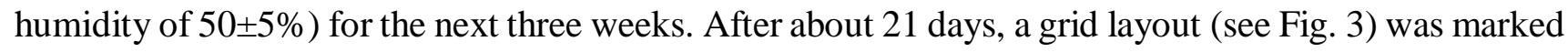
on the slabs to core cylindrical FRGC samples having a dimension of $\varnothing 50 \mathrm{~mm} \times 110 \mathrm{~mm}$ from each square cross-section. An end surface grinder was used to ground these cored samples to a final size of $\varnothing 50 \mathrm{~mm} \times 100 \pm 1 \mathrm{~mm}$ along with unreinforced counterparts to provide smooth bearing ends for loading during the tests. Figs. 3(b) and 3(c) show the final prepared samples. 


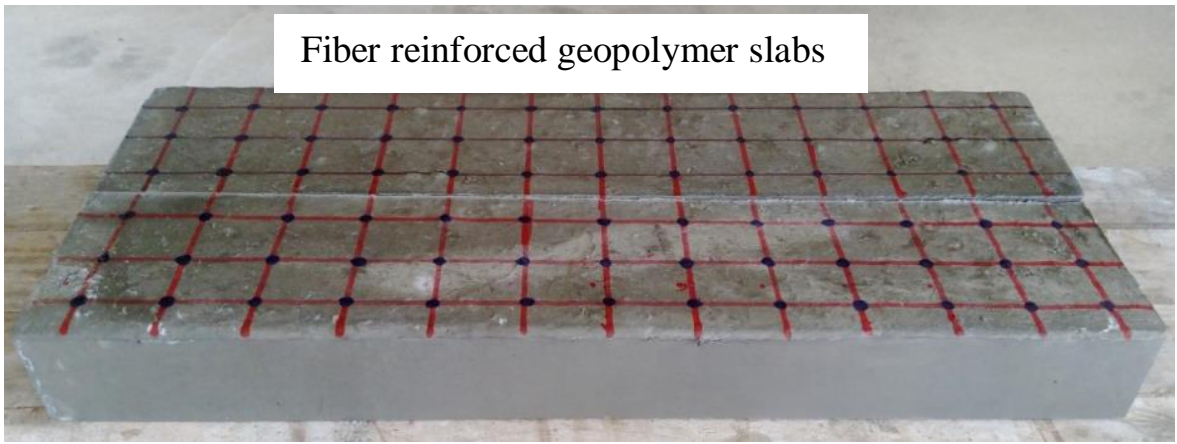

(a)

3

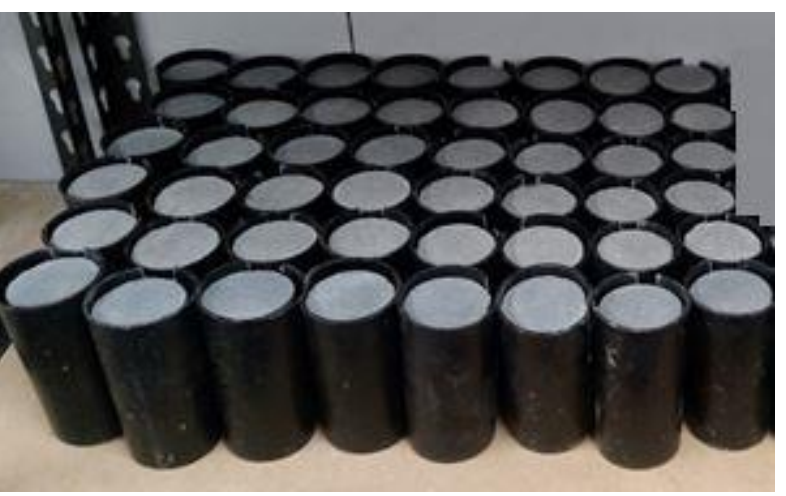

(b)

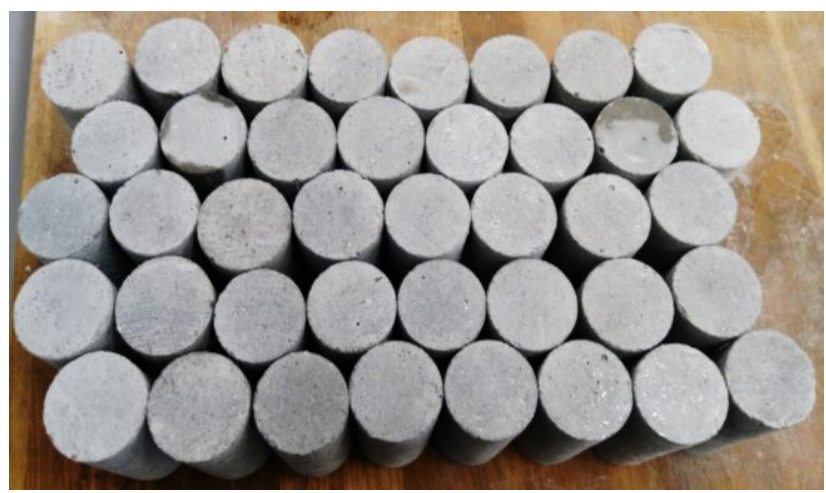

(c)

Fig. 3. (a) Cast slab and prepared samples (b) HSG and (c) FRGC for uniaxial and triaxial tests

\subsection{Test Procedures - Uniaxial and Triaxial compression test setup}

All the uniaxial and triaxial compression tests were performed between the ages of 90 and 120 days after casting using the MTS 815 servo-hydraulic closed-loop equipment. The machine has a very stiff rigid frame rated at $11.0 \times 10^{9} \mathrm{~N} / \mathrm{m}$ and the maximum load capacity of $4.60 \times 10^{6} \mathrm{~N}$, whereas the triaxial Hoek cell is capable of applying a confining pressure of up to140 MPa on $50 \mathrm{~mm} \times 100 \mathrm{~mm}$ sample.

During each test, the triaxial Hoek cell was pressurized with the confining fluid using a confining pressure intensifier, while the confining pressure $\left(\sigma_{3}\right)$ was measured directly with an inbuilt pressure transducer inside the intensifier. However, to prevent the penetration of confining fluid inside the samples during pressurization, the specimens were covered with $2 \mathrm{~mm}$ thick rubber bladder before each 
1 triaxial test. Two linear variable differential transducers (LVDTs) attached to either side, and a

2 circumferential extensometer at mid-height of the sample recorded the axial and lateral displacements

3 of the samples. It is relevant to mention that for the measurement of strain, generally the clip gauges

4 are considered more advantageous in comparison to the electrical strain gauges attached to the surfaces

5 of the test samples since they are capable of capturing the deformation of a much more significant

6 portion of the sample.

\section{$7 \quad$ 2.4.1 Loading schemes}

8 The samples enclosed in rubber membrane were placed between the upper and lower loading caps of

9 the triaxial Hoek cell to perform each test [see Fig. 4(a)]. An actuator applied the axial load in the 10 vertical direction, and appropriate computer commands were programmed to control the servo-

11 hydraulic valve which in turn regulated the confining pressure intensifier via in-vessel pressure

12 transducers. The experiments were controlled digitally, and minicomputers were employed for the data

13 acquisition. For uniaxial compression tests, the loading procedure was controlled in displacement mode

14 from the start at a loading rate of $0.002 \mathrm{~mm} / \mathrm{sec}$, while all samples in triaxial tests were gradually loaded 15 according to the load path shown in Fig. 4 (c). 
Triaxial Hoek cell
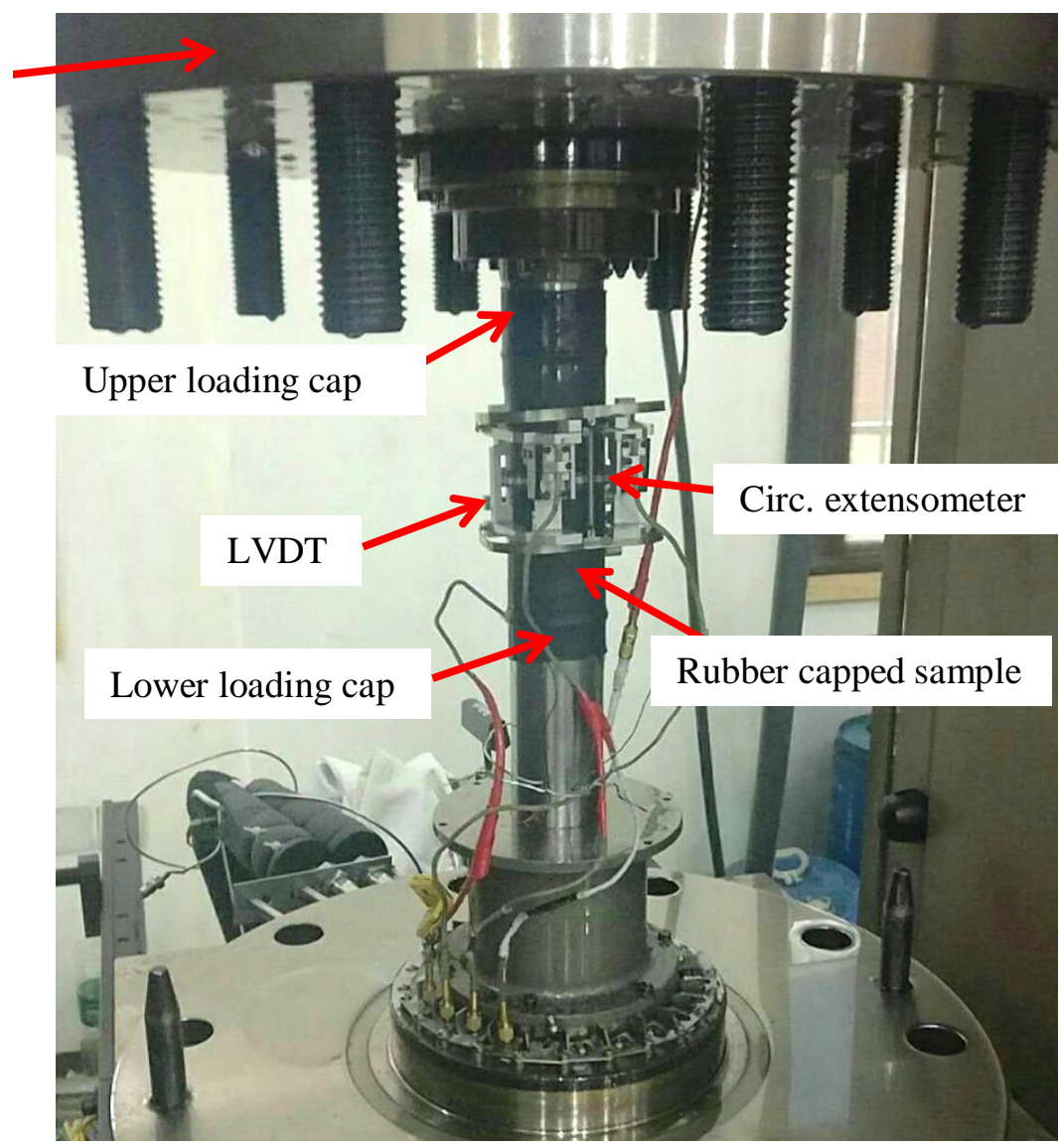

(a)

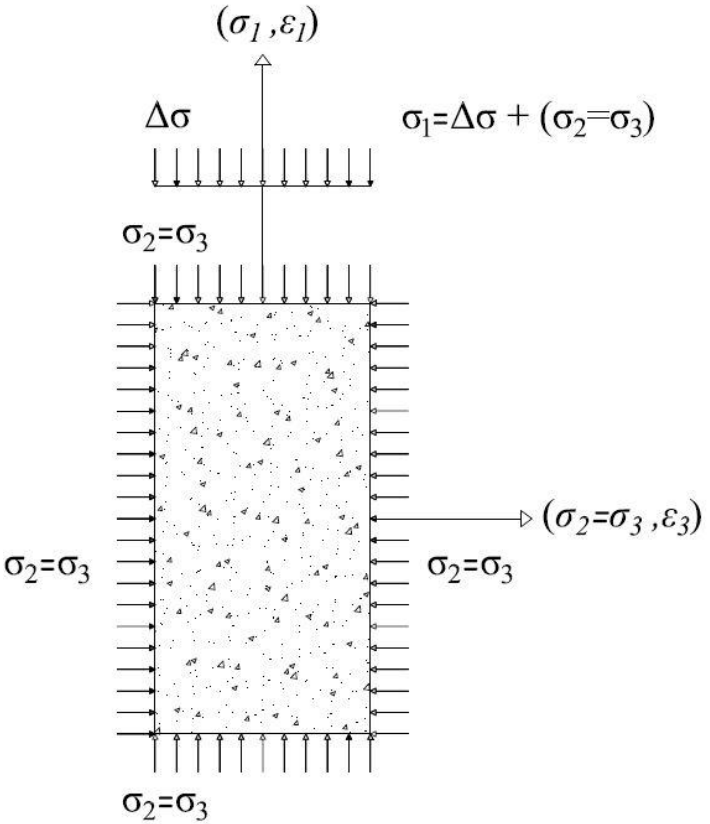

(b)

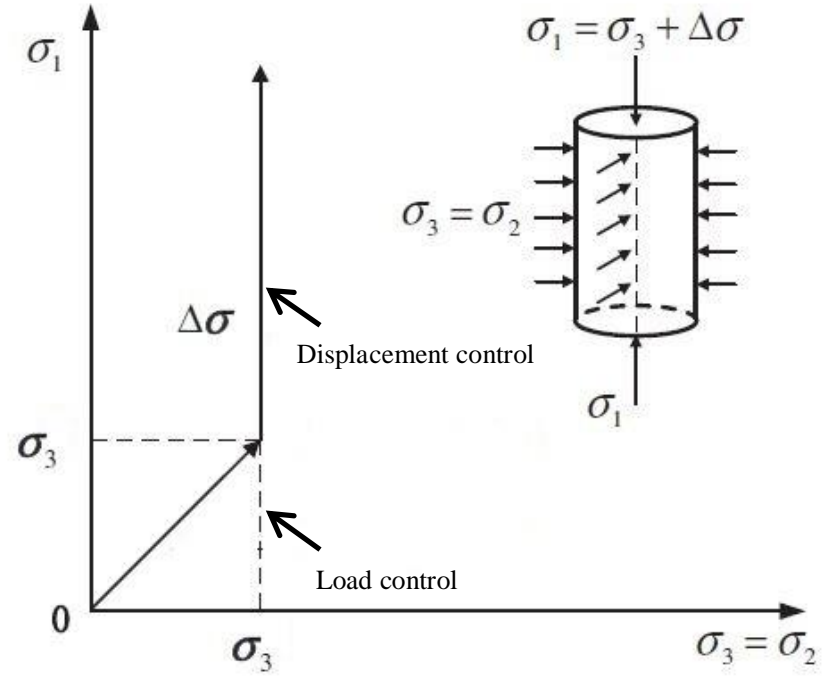

(c) 
Fig. 4. (a) Triaxial test setup (b) Axis direction and (b) Load path for triaxial tests

2 The samples in triaxial compressive tests were subjected to hydrostatic stress initially such that the

3 axial and lateral stresses were applied simultaneously at a loading rate of $0.80 \mathrm{MPa} / \mathrm{sec}$ until the

4 confining pressure $\left(\sigma_{3}\right)$ reached the predetermined target value. At this point, the confining pressure

$5\left(\sigma_{3}\right)$ was held constant, and the additional axial deviatoric stress $\left(\Delta \sigma=\sigma_{1}-\sigma_{3}\right)$ was increased in the

6 displacement mode at a loading rate of $0.002 \mathrm{~mm} / \mathrm{sec}$ up to the sample failure or strain within the

7 samples reaching the measuring range of the extensometers. It is pertinent to mention that at times

8 during the triaxial tests, the increasing application of deviatoric stress $(\Delta \sigma)$ may cause the samples to

9 dilate or contract, hence, resulting in loss or increase of the confining pressure. As a result, to keep the

10 confining pressure constant, some confining fluid must be injected into or drained from the triaxial

11 Hoek cell. For this, hydraulic valves were used to relax or compress the confining fluid to accommodate

12 a specific volume of oil in or out of the cell. The said approach allowed keeping the confining pressure

13 constant within $\pm 0.5 \%$ accuracy.

14 From the view of plasticity, application of varying lateral confining pressures leads to different lodge

15 angles, thus allowing the trace of failure curve in the deviatoric plane. Table 4 shows the details of the 16 complete test program with a total of 15 different confinement ratios $\left(\sigma_{3} / f^{\prime}{ }_{c}\right)$ that were considered.

17 Moreover, at each confinement level, on average at least three replicate were tested. The peak axial 18 stress $\left(\sigma_{l}\right)$ was obtained with the summation of confining stress $\left(\sigma_{3}\right)$ and the deviatoric stress $\left(\Delta \sigma ; F_{o} / A_{s}\right)$, 19 where $F_{o}$ is the deviatoric load and $A_{s}$ is the cross-sectional area of the sample. 
1 Table 4 Experimental program for uniaxial and triaxial compression tests

\begin{tabular}{|c|c|c|c|c|c|}
\hline \multirow{2}{*}{$\begin{array}{l}\text { Serial } \\
\text { No }\end{array}$} & \multirow{2}{*}{$\begin{array}{l}\text { Confining } \\
\text { Pressure (MPa) }\end{array}$} & \multicolumn{2}{|c|}{$\begin{array}{l}\text { High strength geopolymer mix } \\
\text { (HSG) }\end{array}$} & \multicolumn{2}{|c|}{$\begin{array}{l}\text { Fiber reinforced geopolymer composite } \\
\text { (FRGC) }\end{array}$} \\
\hline & & $\begin{array}{l}\text { Sample } \\
\text { designation }\end{array}$ & $\begin{array}{l}\text { Confinement ratio } \\
\left(\sigma_{3} / f_{c)}^{\prime}\right.\end{array}$ & $\begin{array}{l}\text { Sample } \\
\text { designation }\end{array}$ & $\begin{array}{l}\text { Confinement ratio } \\
\left(\sigma_{3} / f_{c)}^{\prime}\right.\end{array}$ \\
\hline 1 & 0 (Uniaxial) & HSG - 0 & 0.0 & FRGC - 0 & 0.0 \\
\hline 2 & 2 & HSG - 2 & 0.021 & FRGC - 2 & 0.022 \\
\hline 3 & 4 & HSG - 4 & 0.042 & FRGC - 4 & 0.044 \\
\hline 4 & 8 & HSG - 8 & 0.084 & FRGC - 8 & 0.089 \\
\hline 5 & 10 & HSG - 10 & 0.104 & FRGC - 10 & 0.112 \\
\hline 6 & 12 & HSG - 12 & 0.125 & FRGC - 12 & 0.134 \\
\hline 7 & 16 & HSG - 16 & 0.170 & FRGC - 16 & 0.178 \\
\hline 8 & 20 & HSG - 20 & 0.208 & FRGC - 20 & 0.223 \\
\hline 9 & 25 & HSG - 25 & 0.260 & FRGC - 25 & 0.278 \\
\hline 10 & 30 & HSG - 30 & 0.312 & FRGC - 30 & 0.334 \\
\hline 11 & 40 & HSG - 40 & 0.416 & FRGC - 40 & 0.445 \\
\hline 12 & 50 & HSG - 50 & 0.520 & FRGC - 50 & 0.556 \\
\hline 13 & 60 & HSG - 60 & 0.625 & FRGC - 60 & 0.667 \\
\hline 14 & 80 & HSG - 80 & 0.834 & FRGC - 80 & 0.889 \\
\hline 15 & 100 & HSG - 100 & 1.041 & FRGC - 100 & 1.120 \\
\hline
\end{tabular}

2

3 3. Results and Discussion

$4 \quad 3.1$ Effect of confining pressure on stress-strain response of HSG

5 The typical stress-strain behaviour of HSG samples under unconfined uniaxial loading condition and

6 confined condition with different confining pressures of $4 \mathrm{MPa}, 12 \mathrm{MPa}, 25 \mathrm{MPa}, 50 \mathrm{MPa}, 80 \mathrm{MPa}$,

7 and $100 \mathrm{MPa}$ are plotted in Fig. 5. It is to be noted that the presented curves show the deviatoric portion

$8\left(\Delta \sigma=\sigma_{1}-\sigma_{3}\right)$ of the tests. Moreover, the axial strain is taken as positive (in compression), while the

9 lateral expansion is designated as negative (tension) in the graphs. As observed, the unreinforced 10 geopolymer mortar samples exhibited high-compressive strength $\left(96 \mathrm{MPa}, \sigma_{3}=0 \mathrm{MPa}\right)$ and showed a

11 linear elastic, perfectly brittle response in uniaxial compression. The three tested samples failed 
1 abruptly once their lateral deformation exceeded the tensile capacity of the material, hence displaying

2 an average critical axial strain $\left(\varepsilon_{c u}\right)$ of $0.29 \pm 0.02 \%$ at the ultimate load.

3 For tests with confinement, all HSG samples experienced softening behaviour after the peak stress. The

4 peak axial stress (obtained from the summation of deviatoric stress and the confining pressure, $\left(\sigma_{l}=\right.$

$\left.\left.5 \Delta \sigma+\sigma_{3}\right)\right)$ and axial strain increased from the beginning to ultimate load, and an apparent non-linearity

6 is observed both in the pre- and post-peak loading regions of the stress-strain curves. By comparing the

7 stress-strain curves, it can be seen that the peak axial stress improved from $96 \mathrm{MPa}$ in the uniaxial

8 compression $\left(\sigma_{3}=0 \mathrm{MPa}\right)$ to deviatoric strengths $(\Delta \sigma)$ of $148 \mathrm{MPa}, 235 \mathrm{MPa}$, and $244 \mathrm{MPa}$ under the

9 lateral confinements of $4 \mathrm{MPa}, 50 \mathrm{MPa}$, and $100 \mathrm{MPa}$, respectively; hence, signifying an overall

10 increase of $58 \%, 216 \%$, and $258 \%$ in the triaxial strength of HSG. The results for the other test cases

11 are summarized in Table 5.

12 As such, it is evident that the increase in lateral confinement from 0 to $100 \mathrm{MPa}$ has a remarkable effect

13 on the triaxial strength of HSG samples. The peak axial strength and ductility of HSG samples increased

14 with an increase in the confining pressure, and pseudo-ductile responses were observed under the

15 triaxial compressive stress conditions. Moreover, it can also be concluded that the increment in peak

16 axial stress and critical axial strain of HSG samples is associated with the confining pressure, i.e., the

17 higher the confinement, the more significant the increase in peak axial stress and the samples behaved

18 more ductile. Similarly, the initial elastic modulus of HSG samples was noticed to vary slightly once

19 the confining pressure was increased from 0 to $100 \mathrm{MPa}$, while a minor reduction in stiffness was also

20 observed as the specimens reached their maximum load carrying capacity. 


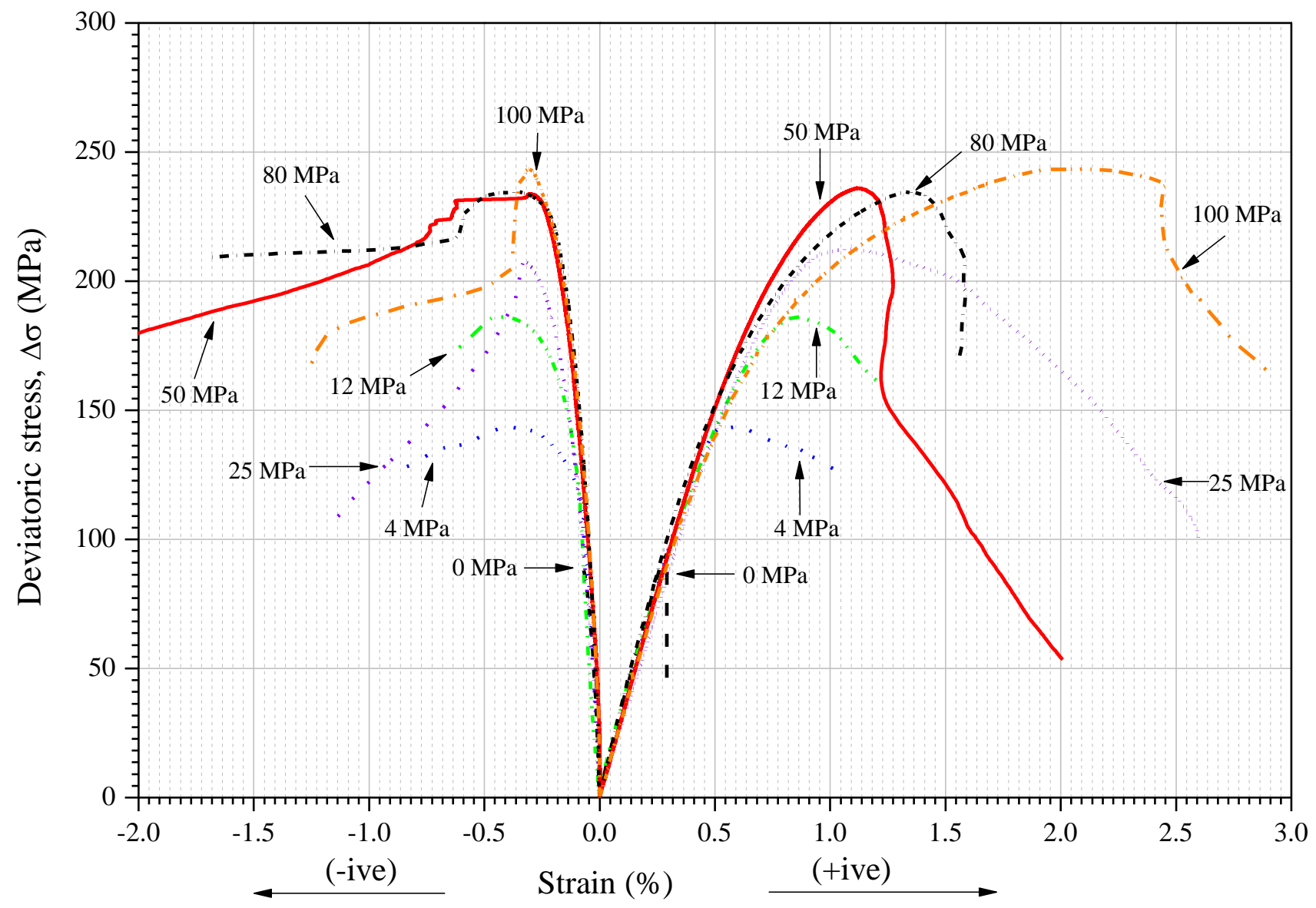

Fig. 5. Uniaxial and triaxial stress-strain behaviour of HSG under various confining pressures

Generally, the main reason for an increase in the deviatoric strength of confined HSG is partially related

to the inter-particle friction between the fractured surfaces along with the contribution made by shear resistance of the geopolymer matrix. It is believed that random cracks and pores always exist in concrete-like materials primarily due to the shrinkage of the cement slurry pastes or local compression from drying of the wet mixtures etc. Upon the application of axial stress, these "flaws" tend to propagate until one or numerous large cracks are formed. At a load level of around $40 \%$ of the peak load, not only the cracks become wider but also the ruptured surfaces tend to lose the contact between themselves. However, with lateral confinement holding these surfaces together; the inter-particle frictional forces may continue to support the additional axial load which is generally higher than the unconfined loading 
1 case [34]. Some other researchers believe that the early application of hydrostatic pressure during the

2 triaxial tests delays the formation of microcrack damage due to shear; hence increasing the load

3 carrying capacity of concrete-like materials upon confinement $[35,36]$.

4 In general, HSC mixtures are characterized to have lower porosity in comparison to the conventional 5 concrete mixes and are found less sensitive to the influence of confinement. For the present case, HSG 6 samples have a cumulative porosity of 7.93\% [9]. In this study as well, the increase in peak axial stress 7 of HSG samples is more pronounced at lower levels than at higher confining pressures. This, on one 8 hand, is in complete agreement to the experimental results reported by Ansari and Li [21] and Mander 9 et al. [37] in the past, where a similar rate of increase in deviatoric strength was observed for high 10 strength concrete (HSC, $100 \mathrm{MPa})$ mixtures at these confinement ratios [i.e. $\left(\sigma_{3} / f^{\prime}{ }_{c}\right)$ of 0.40 and 11 beyond]. On the other hand, it is assumed that the difference in binding gels formed during the 12 geopolymerization process may have also contributed to the observed mechanical behaviour. It is well established that in geopolymerization reaction, the mechanical strength develops from the formation of

14 sodium aluminosilicate hydrate (N-A-S-H) gel network or combination of calcium aluminum silicate hydrates $(\mathrm{C}-\mathrm{A}-\mathrm{S}-\mathrm{H})$ in the presence of slag.

Although the exact mechanism for the geopolymerization process has not been understood completely,

17 according to Davidovits [38], it can be schematized as an imaginary polycondensation of orthosilicate 18 ions. Unlike the OPC's chemical reaction, where water is continuously required for the completion of 19 hydration process; in case of the geopolymerization, it is one of the end products produced during the 20 polycondensation and hardening process of oligomers [39]. The excluded water remains either free or 21 bound within final reaction products and has no role to play in the geopolymerization process, leaving 22 behind a discontinuous nano-porous structure regarded beneficial for the performance of geopolymers 23 [40]. It is presumed that owing to the low porosity of HSG samples and the possible presence of water 
1 in the test samples that could have remained in the microstructure during the curing and further drying

2 periods, a slight increase in the pore pressure upon the application of higher lateral confinements may

3 have occurred. This is understood to have resulted in the lower increment in deviatoric/shear strength

4 of HSG samples at higher confining pressures. However, additional tests along with pore pressure

5 measurements are suggested to be carried out in future studies to validate this assumption.

\subsection{Effect of confining pressure on stress-strain response of FRGC}

7 Fig. 6 shows the typical stress-strain relations of FRGC samples under uniaxial and triaxial compressive

8 stress states. It can be seen that the FRGC samples exhibited higher ductility without evidencing the

9 sudden breakage of cylinders in uniaxial compression tests. The critical axial strain $\left(\varepsilon_{c u}\right)$ of HSG

10 samples increased from $0.29 \pm 0.02 \%$ to $0.54 \pm 0.05 \%$, resulting in an overall increase of $86 \%$ in the

11 strain capacity of geopolymer. It is believed that the percentage increase in ductility is due to the

12 improvement in the tensile capacity of HSG samples with the addition of hybrid-fiber reinforcement.

13 However, the maximum load carrying capacity of FRGC samples was slightly lower than the

14 unreinforced counterparts, i.e., $90 \mathrm{MPa}$. It can also be observed that the FRGC samples had a lower

15 stiffness which is mainly due to the higher elongation capacity of HSPE (3.30\%) fibers.

16 The main reason for the reduction in compressive strength of FRGC samples is primarily associated

17 with the inclusion of synthetic fibers. It has been noticed that polyethylene fibers tend to reduce the

18 shear strength of concrete mainly because of the formation of air voids around the fiber-matrix interface

19 which have also been reported by other researchers [41, 42]. However, a three-fold increase in flexural

20 tensile strength and toughness of HSG material is possible using the proposed hybrid-fiber

21 reinforcement due to an improvement in the slip-forming characteristics and increased cohesiveness of

22 fiber reinforced geopolymer mixture. Further details on this aspect may be found in [29]. 


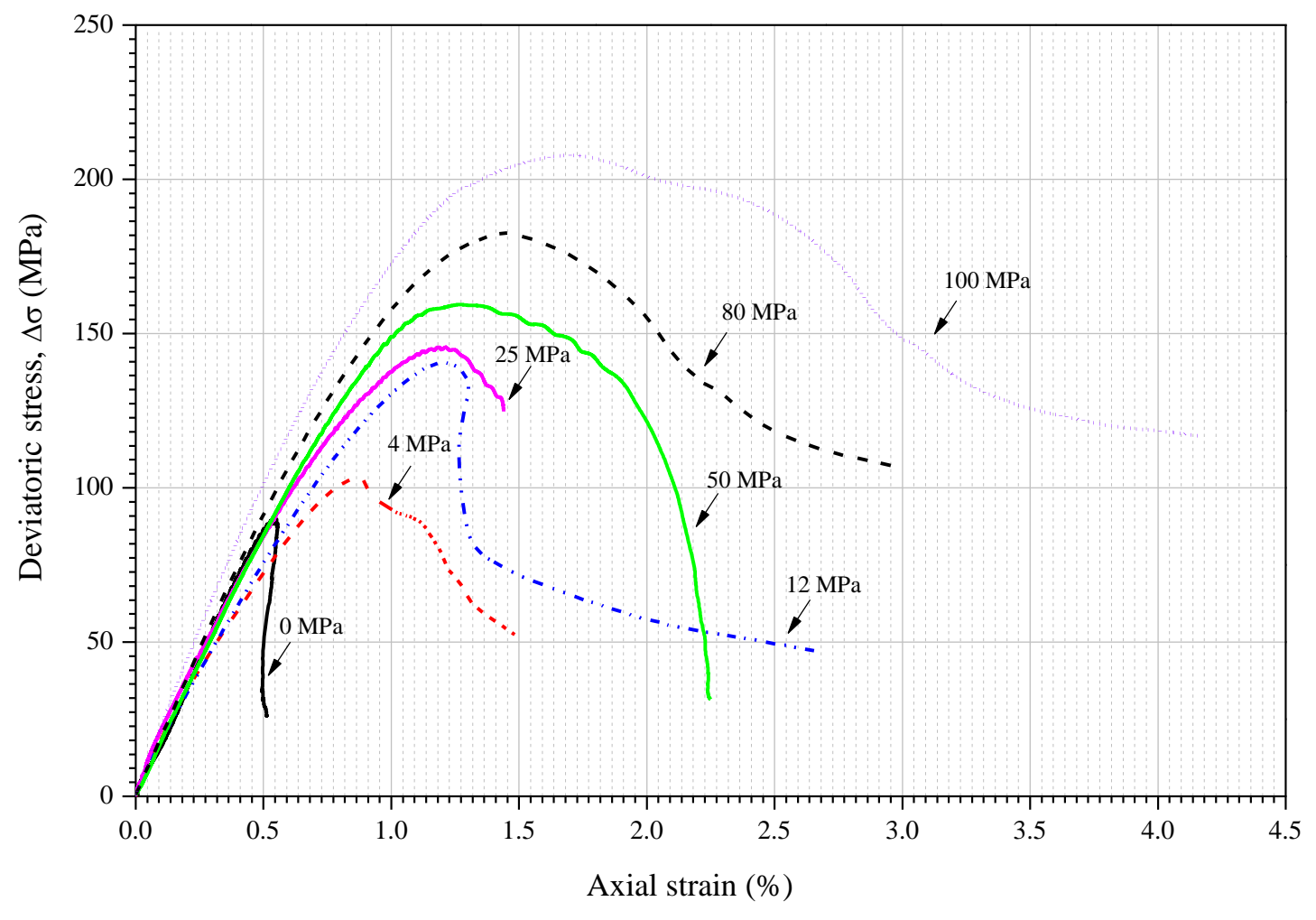

2 Fig. 6. Uniaxial and triaxial stress-strain behaviour of FRGC under various confining pressures

3 In the context of the present research, from Fig. 6, it is evident that the peak axial strength of FRGC

4 samples has increased from $90 \mathrm{MPa}$ to deviatoric strengths $(\Delta \sigma)$ of $103.11 \mathrm{MPa}, 164.35 \mathrm{MPa}$, and $5207.82 \mathrm{MPa}$ under the confining pressures of $4 \mathrm{MPa}, 50 \mathrm{MPa}$, and $100 \mathrm{MPa}$, respectively. Hence,

6 showing an increase of $19 \%, 138 \%$, and $242 \%$ in the axial strength of fiber reinforced geopolymer

7 samples with lateral confinement. Moreover, it can also be seen that in comparison to unreinforced 8 geopolymer samples, the rate of increase in deviatoric strength for FRGC samples is lower at any given

9 level of medium confining pressure. On the other hand, a distinct rise in peak axial stress was noticed 10 for FRGC samples at higher confining pressures (i.e., $80 \mathrm{MPa}$ or $100 \mathrm{MPa}$ ) which are different from 11 the unreinforced counterparts. The strength characteristics of FRGC under triaxial compression apart 12 from those reflected in Fig. 6 such as peak axial stress $\left(\sigma_{l}\right)$, failure strength ratio $\left(\sigma_{l} / f^{\prime}{ }^{\prime}\right)$, critical axial 13 strains $\left(\varepsilon_{1},\right)$ are summarized in Table 6. 
1 Table 5 Uniaxial and Triaxial compression test results of HSG samples

\begin{tabular}{|c|c|c|c|c|c|c|c|c|c|}
\hline $\begin{array}{l}\text { Sample } \\
\text { Designation }\end{array}$ & $f_{c}^{\prime}$ & $\begin{array}{l}\text { Confinement } \\
\text { pressure }\end{array}$ & $\begin{array}{l}\text { Confinement } \\
\text { ratio }\end{array}$ & $\begin{array}{l}\text { Confined Peak } \\
\text { axial stress, } \sigma_{l}\end{array}$ & $\begin{array}{l}\text { Failure } \\
\text { strength ratio }\end{array}$ & $\begin{array}{l}\text { Percentile } \\
\text { increase in } \\
\text { strength }\end{array}$ & $\begin{array}{l}\text { Confined Peak } \\
\text { axial strain, } \varepsilon_{1}\end{array}$ & $\begin{array}{l}\text { Confined Peak } \\
\text { lateral strain, } \varepsilon_{3}\end{array}$ & $\begin{array}{l}\text { Modulus of } \\
\text { Elasticity, E }\end{array}$ \\
\hline & (MPa) & (MPa) & $\left(\sigma_{3} / f_{c}^{\prime}\right)$ & (MPa) & $\left(\sigma_{1} / f_{c}^{\prime}\right)$ & $(\%)$ & $(\%)$ & $(\%)$ & (GPa) \\
\hline HSG - 0 & 96 & 0 & 0.0 & $96.00 \pm 0.68$ & 1.00 & - & $0.293 \pm 0.020$ & $-0.079 \pm 0.0030$ & $34.51 \pm 0.34$ \\
\hline HSG - 2 & 96 & 2 & 0.021 & $132.66 \pm 5.11$ & 1.38 & 38 & $0.423 \pm 0.036$ & $-0.386 \pm 0.0017$ & $35.75 \pm 2.79$ \\
\hline HGS - 4 & 96 & 4 & 0.042 & $151.58 \pm 4.55$ & 1.57 & 57 & $0.587 \pm 0.014$ & $-0.391 \pm 0.0223$ & $32.09 \pm 0.56$ \\
\hline HSG - 8 & 96 & 8 & 0.084 & $172.71 \pm 1.18$ & 1.79 & 79 & $0.603 \pm 0.039$ & $-0.405 \pm 0.0308$ & $35.44 \pm 1.81$ \\
\hline HSG - 10 & 96 & 10 & 0.104 & $187.22 \pm 5.07$ & 1.95 & 95 & $0.738 \pm 0.010$ & $-0.380 \pm 0.0368$ & $33.02 \pm 2.19$ \\
\hline HSG - 12 & 96 & 12 & 0.125 & $198.91 \pm 3.98$ & 2.07 & 107 & $0.856 \pm 0.024$ & $-0.423 \pm 0.0141$ & $31.54 \pm 1.03$ \\
\hline HSG - 16 & 96 & 16 & 0.170 & $213.14 \pm 3.76$ & 2.22 & 122 & $0.789 \pm 0.025$ & $-0.257 \pm 0.0186$ & $32.72 \pm 0.68$ \\
\hline HSG - 20 & 96 & 20 & 0.208 & $225.75 \pm 1.68$ & 2.35 & 135 & $0.887 \pm 0.013$ & $-0.453 \pm 0.0344$ & $32.55 \pm 1.96$ \\
\hline HSG - 25 & 96 & 25 & 0.260 & $237.45 \pm 3.49$ & 2.47 & 147 & $1.089 \pm 0.074$ & $-0.321 \pm 0.0239$ & $32.88 \pm 3.65$ \\
\hline HSG - 30 & 96 & 30 & 0.312 & $252.04 \pm 9.84$ & 2.63 & 163 & $1.096 \pm 0.107$ & $-0.277 \pm 0.0748$ & $33.80 \pm 0.19$ \\
\hline HSG - 40 & 96 & 40 & 0.416 & $267.49 \pm 6.70$ & 2.78 & 178 & $1.120 \pm 0.083$ & $-0.326 \pm 0.0750$ & $33.66 \pm 0.94$ \\
\hline HSG - 50 & 96 & 50 & 0.520 & $284.76 \pm 5.05$ & 2.96 & 196 & $1.122 \pm 0.048$ & $-0.302 \pm 0.0120$ & $34.93 \pm 2.19$ \\
\hline HSG - 60 & 96 & 60 & 0.625 & $291.13 \pm 3.13$ & 3.03 & 203 & $1.091 \pm 0.065$ & $-0.285 \pm 0.0146$ & $32.21 \pm 1.06$ \\
\hline HSG - 80 & 96 & 80 & 0.834 & $315.01 \pm 1.08$ & 3.28 & 228 & $1.328 \pm 0.018$ & $-0.345 \pm 0.0051$ & $34.14 \pm 1.94$ \\
\hline HSG - 100 & 96 & 100 & 1.104 & $344.98 \pm 6.30$ & 3.59 & 259 & $2.117 \pm 0.073$ & $-0.307 \pm 0.0218$ & $30.99 \pm 1.74$ \\
\hline
\end{tabular}


1 Table 6 Uniaxial and Triaxial compression test results of FRGC samples

\begin{tabular}{|c|c|c|c|c|c|c|c|c|c|}
\hline $\begin{array}{l}\text { Sample } \\
\text { Designation }\end{array}$ & $f_{c}^{\prime}$ & $\begin{array}{l}\text { Confinement } \\
\text { pressure }\end{array}$ & $\begin{array}{l}\text { Confinement } \\
\text { ratio }\end{array}$ & $\begin{array}{l}\text { Confined Peak } \\
\text { axial stress, } \sigma_{l}\end{array}$ & $\begin{array}{l}\text { Failure } \\
\text { strength ratio }\end{array}$ & $\begin{array}{l}\text { Percentile } \\
\text { increase in } \\
\text { strength }\end{array}$ & $\begin{array}{l}\text { Confined Peak } \\
\text { axial strain, } \varepsilon_{1}\end{array}$ & $\begin{array}{l}\text { Confined Peak } \\
\text { lateral strain, } \varepsilon_{3}\end{array}$ & $\begin{array}{l}\text { Modulus of } \\
\text { Elasticity, E }\end{array}$ \\
\hline & $(\mathrm{MPa})$ & $(\mathrm{MPa})$ & $\left(\sigma_{3} / f^{\prime}{ }_{c}\right)$ & (MPa) & $\left(\sigma_{1} / f^{\prime}{ }_{c}\right)$ & $(\%)$ & $(\%)$ & $(\%)$ & (GPa) \\
\hline FRGC - 0 & 90 & 0 & 0.0 & $90.00 \pm 2.95$ & 1.00 & - & $0.542 \pm 0.051$ & - & $17.56 \pm 0.25$ \\
\hline FRGC - 2 & 90 & 2 & 0.022 & $95.25 \pm 5.79$ & 1.06 & 6 & $0.654 \pm 0.020$ & - & $16.84 \pm 2.50$ \\
\hline FRGC - 4 & 90 & 4 & 0.044 & $107.11 \pm 4.37$ & 1.19 & 19 & $0.868 \pm 0.024$ & - & $16.47 \pm 0.12$ \\
\hline FRGC - 8 & 90 & 8 & 0.089 & $130.76 \pm 4.69$ & 1.45 & 45 & $1.024 \pm 0.076$ & - & $18.23 \pm 0.73$ \\
\hline FRGC - 10 & 90 & 10 & 0.112 & $136.15 \pm 2.08$ & 1.52 & 52 & $0.981 \pm 0.027$ & - & $15.92 \pm 0.36$ \\
\hline FRGC - 12 & 90 & 12 & 0.134 & $151.02 \pm 0.80$ & 1.68 & 68 & $1.202 \pm 0.043$ & - & $15.67 \pm 0.29$ \\
\hline FRGC - 16 & 90 & 16 & 0.178 & $143.99 \pm 7.84$ & 1.59 & 59 & $1.064 \pm 0.031$ & - & $17.98 \pm 0.39$ \\
\hline FRGC - 20 & 90 & 20 & 0.223 & $146.94 \pm 1.95$ & 1.64 & 64 & $1.012 \pm 0.016$ & - & $16.94 \pm 0.14$ \\
\hline FRGC - 25 & 90 & 25 & 0.278 & $170.45 \pm 0.36$ & 1.89 & 89 & $1.183 \pm 0.110$ & - & $17.70 \pm 0.91$ \\
\hline FRGC - 30 & 90 & 30 & 0.334 & $176.04 \pm 1.75$ & 1.96 & 96 & $1.217 \pm 0.105$ & - & $17.46 \pm 0.43$ \\
\hline FRGC - 40 & 90 & 40 & 0.445 & $188.61 \pm 0.45$ & 2.09 & 109 & $1.262 \pm 0.031$ & - & $17.48 \pm 1.31$ \\
\hline FRGC - 50 & 90 & 50 & 0.556 & $214.35 \pm 2.66$ & 2.38 & 138 & $1.274 \pm 0.058$ & - & $17.78 \pm 0.81$ \\
\hline FRGC - 60 & 90 & 60 & 0.667 & $231.12 \pm 2.01$ & 2.57 & 157 & $1.317 \pm 0.060$ & - & $19.39 \pm 0.92$ \\
\hline FRGC - 80 & 90 & 80 & 0.889 & $262.70 \pm 9.54$ & 2.92 & 192 & $1.500 \pm 0.036$ & - & $19.21 \pm 0.71$ \\
\hline FRGC - 100 & 90 & 100 & 1.120 & $307.82 \pm 2.84$ & 3.42 & 242 & $2.201 \pm 0.064$ & - & $20.82 \pm 0.68$ \\
\hline
\end{tabular}


1 Unfortunately, the circumferential extensometer malfunctioned when the tests were conducted on

2 FRGC samples, and the test readings about the lateral expansion of FRGC samples could not be

3 recorded. Nevertheless, since the primary objective of this research is to study the influence of

4 confinement on the peak axial strength and deformation characteristics of high strength geopolymer

5 composites, the test results pertaining to the increase in axial strength and axial strain for FRGC samples

6 at different confining pressures are presented and compared with those of unreinforced HSG samples.

7 The influence of fiber addition on enhancing the deformability of high-strength geopolymer matrix at

8 varying levels of confining pressures is apparent (see Fig. 7). As such in Fig. 7, the ductility increase

9 for both types of materials under the influence of confinement is normalized against the critical axial

10 strain of HSG under uniaxial compression.

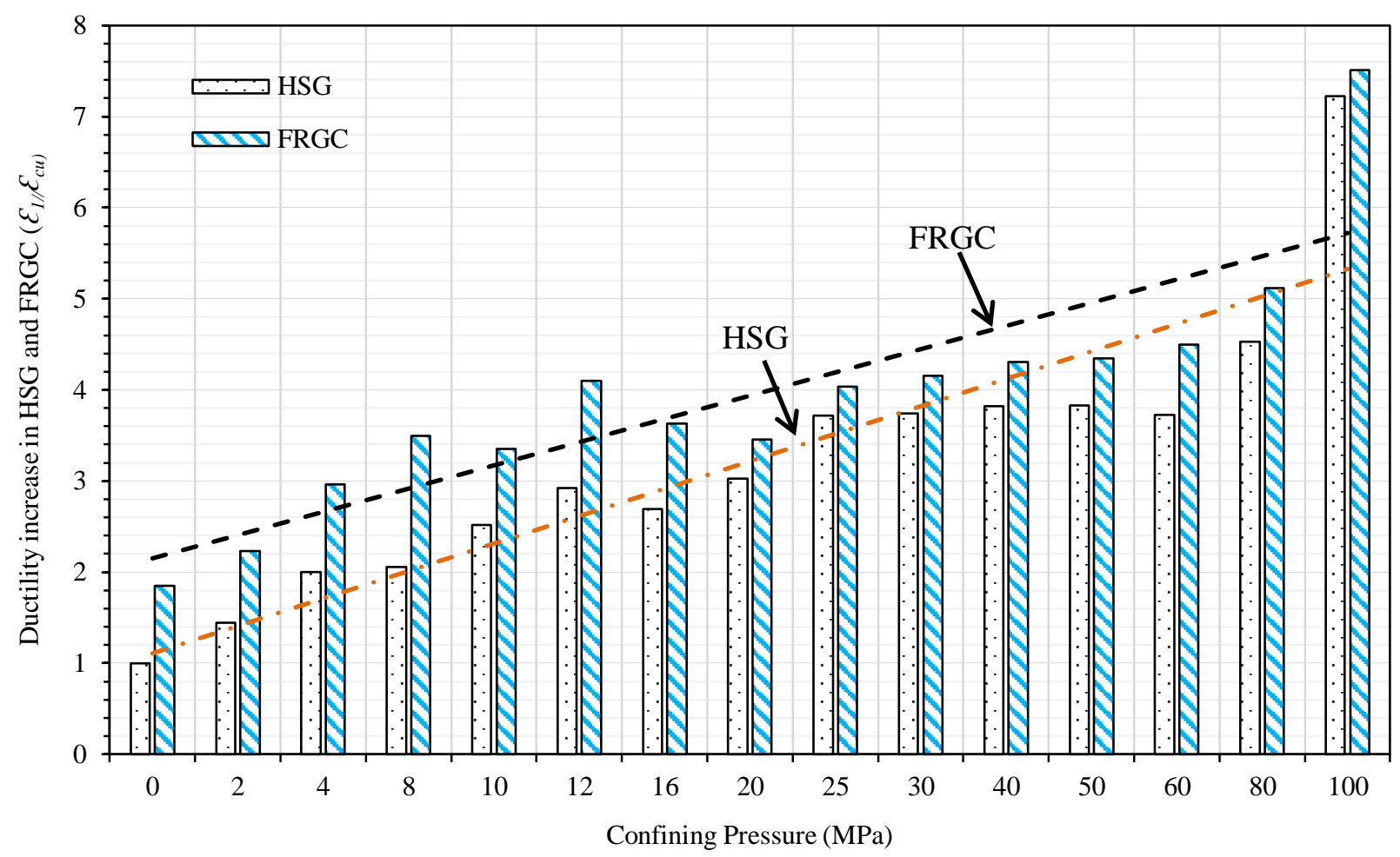

12 Fig. 7. Comparison of increase in ductility of HSG and FRGC at different confining pressures 
1 It may be seen that at any given level of confining pressure, the critical axial strain in FRGC samples

2 is higher than that of unreinforced geopolymer matrix. On the one hand, this specifies that the addition

3 of hybrid-fiber reinforcement has implicitly improved the ductility of HSG matrix. On the other hand,

4 it can also be observed that the increasing application of confining pressure appears to have a limiting

5 effect on the ductility of FRGC samples, meaning the presence of fibers in test samples is more

6 beneficial in improving the critical axial strain of HSG samples at low levels of lateral confinement.

7 Some previous investigations conducted by Lu and Hsu [26] and Noori et al. [43] have reported similar

8 outcomes, where the addition of steel fiber reinforcement in different volume fractions (1\% and $2 \%)$

9 did not show any improvement in the ductility of high-performance concrete mixtures. Instead, the

10 relationship between the critical axial strains at peak stress for steel fiber reinforced high strength

11 concrete had lower coefficients than the unreinforced counterparts.

\subsection{Effect of confining pressure on triaxial strength of HSG and FRGC}

13 The current section presents the analyses in regards to the increase in peak axial strength as a function

14 of confining pressure for both types of materials. However, before discussing the results, brief

15 information on the shape of concrete failure envelope and failure criteria used in the past is provided.

16 It should be noted that some of these failure criteria were developed initially for soils and rocks and

17 then later extended for OPC concrete. Moreover, among the different types of failure criteria, Mohr-

18 coulomb's linear failure criterion often remains the first choice in describing the strength behaviour of

19 concrete-like materials upon confinement due to its simplicity and relatively good accuracy.

However, one of the main disadvantages of this failure criterion is primarily related to the shape of the

21 described compressive and tensile meridians on the strength envelope, which are all straight lines. It

22 has been observed that the proposed compressive and tensile meridians become far deviant from the 
1 actual strength surface when the mean principal stress is high. Similarly, the failure surface in the

2 deviatoric plane is not smooth and inconsistent to the consensus reported by many researchers, e.g. [21,

3 26]. Some other triaxial failure criteria include the two-parameter Drucker-Prager's failure criterion,

4 four-parameter Ottosen's failure criterion, and four-parameter Hsieh-Ting-Chen's criterion [44], etc.

5 In general, as elucidated by Chen [44], the concrete failure surface is typically an open-ended convex

6 polar figure which has a threefold symmetry along the hydrostatic axis. It has a nearly triangular shape

7 for low compressive and tensile stresses in the deviatoric plane. While with an increase in the

8 hydrostatic pressure or mean principal stress; it becomes more circular in the three-dimensional stress

9 space. Furthermore, it has been concluded that the influence of confining pressure on the failure

10 strength is different for ordinary and high strength concrete (HSC) and usually the effect is more

11 pronounced for low strength concrete mixtures [21].

12 An initial examination of the results obtained in this study also suggested that non-linear analyses would

13 establish better correlations for peak axial strength as a function of confining pressure for the studied

14 materials. Therefore, for the present work, Mohr-coulomb's linear failure criterion has not been used

15 due to the above-stated reasons and limited correlation for the test data. Instead, two other failure 16 criteria, i.e., Power-law failure criterion (an extended non-linear form of Mohr-coulomb failure

17 criterion) and Willam-Warnke failure criterion are used to calibrate the models with the triaxial 18 compression results of HSG and FRGC. Of note, these models define the compressive meridian on the 19 failure surface as parabolas regarding the average normal and mean shear stress to fit the curved 20 meridians obtained during the triaxial tests. Further information on these failure criteria is given in the 21 subsequent analyses of the results and discussions.

23 The pressure-dependent power-law failure criterion is given as: 
$1 \quad \frac{\sigma_{1}}{f^{\prime}{ }_{c}}=1+a\left(\sigma_{3} / f^{\prime}{ }^{\prime}\right)^{b}$

2 where, $\sigma_{l}$ denotes the peak axial stress; $\sigma_{3}$ denotes the confining pressure; $f^{\prime}{ }_{c}$ represents the uniaxial 3 compressive strength; and a and $\mathrm{b}$ are the material constants.

4 The variation of peak axial stress $\left(\sigma_{1}\right)$ as a function of the confining pressure $\left(\sigma_{3}\right)$ for HSG and FRGC 5 is illustrated in Figs. 8 and 9, respectively which are normalized against their respective uniaxial 6 compressive strengths $\left(f^{\prime}{ }_{c}\right)$ and compared with previous investigations on cement based counterparts.

7 The non-linear regression analysis of the data in the form of best-fit curves is also shown in these graphs 8 and mathematically described by Eqs. (2) and (3) for HSG and FRGC, respectively.

$9 \quad$ For HSG: $\quad \frac{\sigma_{1}}{f^{\prime}{ }_{c}}=1+2.58\left(\sigma_{3} / f^{\prime}{ }^{\prime}\right)^{0.430}$

$10 \quad$ For FRGC: $\quad \frac{\sigma_{1}}{f^{\prime}{ }_{c}}=1+2.15\left(\sigma_{3} / f^{\prime}{ }^{\prime}\right)^{0.653}$

11 In Fig. 8, it can be seen that at low levels of confinement, a sharp increase in peak axial strength is

12 observed for HSG which tends to reduce as the slope of the failure curve decreases sharply with an 13 increase in the confining pressure. A higher degree of non-linearity exists in the initial portion of the 14 failure curve and is believed to be associated with the unique three-dimensional (N-A-S-H or C-(A)-S$15 \mathrm{H})$ polycondensed binding gel network of geopolymers binders which makes the internal structure of 16 material more compact than the crystalline $\mathrm{C}-\mathrm{S}-\mathrm{H}$ structure formed upon the hydration of OPC.

17 Numerous relations have been proposed in the past to predict the failure strength of confined HSCs. 18 The triaxial compressive strength results of HSCs (having a comparable compressive strength to that of HSG) from the previous studies undertaken by Xie et al. $\left(f^{\prime}{ }_{c}=103 \mathrm{MPa}\right)$ [19], Ansari and Li $\left(f^{\prime}{ }_{c}=\right.$ 
$1107 \mathrm{MPa})$ [21], and Attard et al. $\left(f^{\prime}{ }_{c}=107 \mathrm{MPa}\right)$ [36] are compared with the data obtained for HSG. As

2 such, it can be observed that the rate of increase in failure strength for HSG at low to medium levels of

3 confinement is higher than that of HSCs. A large scatter exists between the triaxial strength results of

4 HSCs from the previous studies which has also been reported by Ansari and Li [21]. However, the

5 exact reason for this discrepancy is not apparent and may require further explanation in future studies.

6 It is believed that the differences in the aspect ratio of the test samples and influence of confining

7 pressures on different material compositions are a few possible reasons for disagreement between these

8 studies.

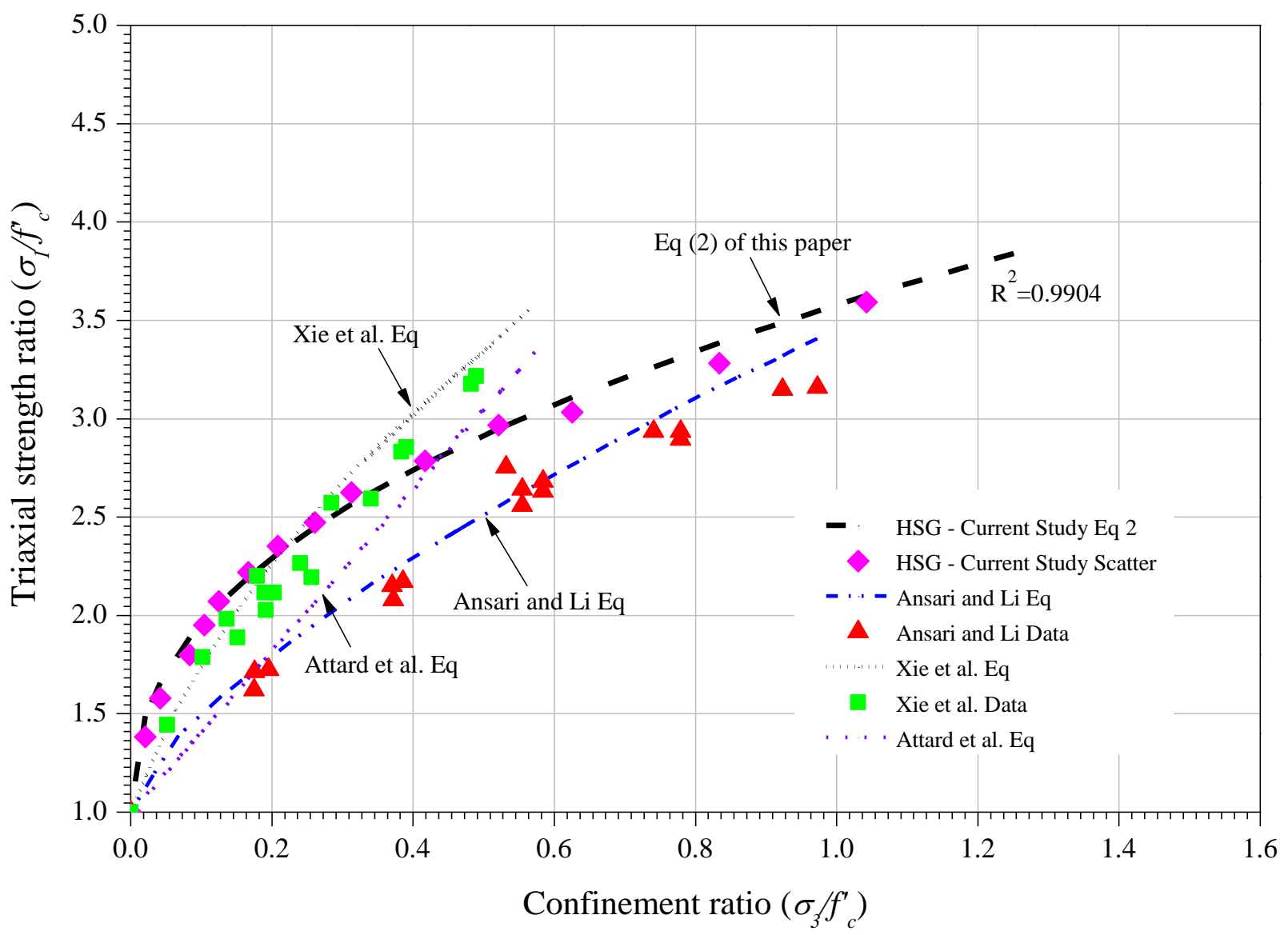

Fig. 8. Triaxial strength of HSG and comparison with previous experimental studies on HSCs 
1 Nevertheless based on the available data, it can be concluded that the test data of Ansari and Li [21]

2 and their suggested failure strength curve for HSC falls well below the defined failure curve of HSG in

3 Eq. (2). On the other hand, the data of Xie et al. [19] lies in the proximity of the current experimental

4 results up to $0.40 f^{\prime}$. However, the empirical equation suggested by Xie et al. [19] does not correlate

5 well with their test data. Besides, it may be seen that their experimental research only involved low

6 levels of confinement. Therefore, it is not possible to predict the trend for the whole range of confining

7 pressures used in this study. On the other hand, Attard et al. [36] proposed a linear relationship between

8 the peak axial strength and the confining pressure for HSC at similar confinement ratios, which is

9 different from the non-linear relationship obtained in the current research and two other previous

10 investigations.

11 Unlike HSCs, limited researchers have investigated the triaxial strength behaviour of fiber reinforced 12 cement composites (FRCCs). In Fig. 9, the data from the present research on FRGC is compared to that 13 of Farnam et al.'s high-performance fiber reinforced concrete (HPFRC) [25], Ren et al.'s ultra-high 14 performance fiber reinforced cement composites (UHPCC) [46], and Noori et al.'s steel fiber reinforced cementitious mortar (SFRCM) [43]. It should be noted that the cement based composites and concretes

16 in these investigations also contained $2 \%$ volumetric ratio of steel fibers, similar to FRGC. From Fig.

179 , it can be seen that the failure curves of cement based composites under low confining pressures from

18 Farnam et al. [25], Ren et al. [45], and Noori et al.'s [43] experiments display a close similarity to the 19 failure strength of FRGC from the current research. In fact, the results reported by Noori et al. [43] 20 follow an identical strength increase behaviour at the relatively low level of confining pressure as 21 reflected by the initial portion of the fitted curve for FRGC.

22 However, with an increase in the confining pressure, the rate of strength increase in FRGC tends to be 23 lower than that of previously studied FRCCs. Moreover, unlike the HSG samples, where a higher 
1 degree of non-linearity was observed in the failure strength curve at low confinement ratios, the

2 influence of confining pressure on the strength increase of FRGC is gradual, and the compressive

3 meridian of FRGC tends to be more linear at higher confinement ratios. A similar tendency was

4 reported in earlier research where fiber reinforced cement composites showed a lower increase in

5 triaxial strength under lower confinement in comparison to plain concrete mixtures [43].

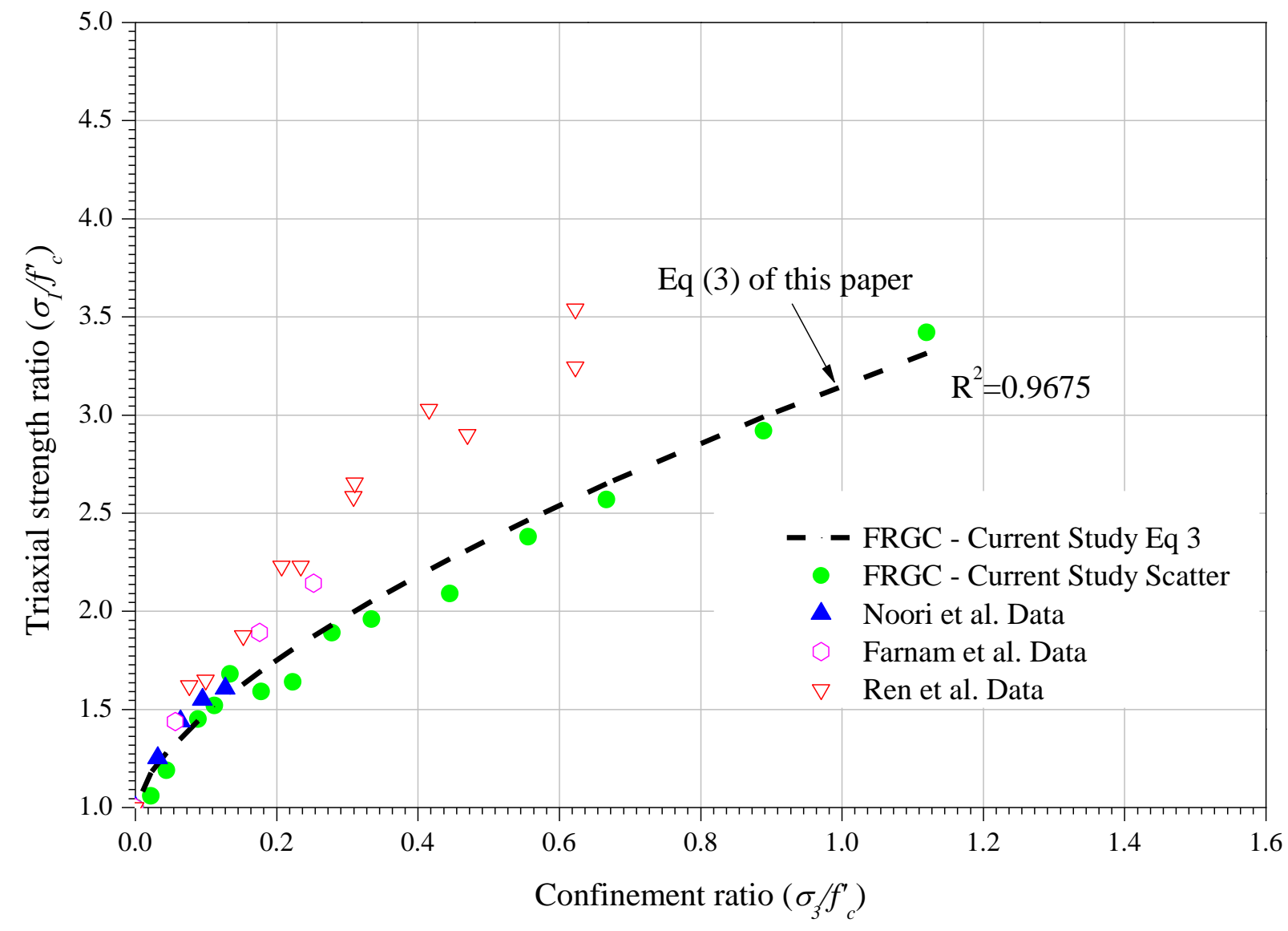

$7 \quad$ Fig. 9. Triaxial strength of FRGC and comparison with previous experimental studies of FRCCs

9 In addition to the Power-law failure criterion, Willam-Warnke five-parameter model is the most 
1 been adopted to establish material models in hydrocodes. In this section, Willam-Warnke five-

2 parameter model is calibrated using the triaxial compression test results of HSG and FRGC samples.

3 This model describes the ultimate strength surface of concrete in terms of the tensile (at $\theta=0^{\circ}$ ) and

4 compressive meridians (at $\theta=60^{\circ}$ ), such that the compressive meridian of the strength surface takes

5 the form of a quadratic parabola and requires only three parameters for its calibration, as expressed in 6 equation (4):

$\frac{\tau_{m}}{f^{\prime}{ }_{c}}=b_{o}+b_{1}\left(\frac{\sigma_{m}}{f^{\prime}{ }_{c}}\right)+b_{2}\left(\frac{\sigma_{m}}{f^{\prime}{ }_{c}}\right)^{2}$

8 where in Eq. 4; $\sigma_{m}=I_{1} / 3=\left(\sigma_{\left.1+\sigma_{2}+\sigma_{3}\right) / 3} ; \quad \tau_{m}=\frac{1}{\sqrt{15}} \sqrt{\left(\sigma_{1}-\sigma_{2}\right)^{2}+\left(\sigma_{2}-\sigma_{3}\right)^{2}+\left(\sigma_{3}-\sigma_{1}\right)^{2}}\right.$

$9 \sigma_{\mathrm{m}}$ and $\tau_{m}$ are the average normal and mean shear stress. $I_{l}$ is the first invariant of the stress tensor; $f^{\prime}{ }_{c}$

10 denotes the uniaxial compressive strength; $\sigma_{1}, \sigma_{2}$ and $\sigma_{3}$ denote the stresses in three principal directions,

11 and $b_{o}, b_{1}$, and $b_{2}$ are the three Willam-Warnke material model coefficients, respectively.

12 For high-strength geopolymer (HSG) and fiber reinforced geopolymer composites (FRGC) tested in

13 the experiments, the compressive meridians as per Willam-Warnke criterion are expressed as follows:

For HSG:

$$
\frac{\tau_{m}}{f^{\prime}{ }_{c}}=0.0684+1.05\left(\frac{\sigma_{m}}{f^{\prime}{ }_{c}}\right)-0.308\left(\frac{\sigma_{m}}{f^{\prime}{ }_{c}}\right)^{2}
$$

15 For FRGC:

$$
\frac{\tau_{m}}{f^{\prime}{ }_{c}}=0.240+0.501\left(\frac{\sigma_{m}}{f{ }^{\prime}}\right)-0.105\left(\frac{\sigma_{m}}{f^{\prime}{ }^{\prime}{ }^{2}}\right)^{2}
$$

Figs. 10 and 11 depict the data scatter and the compressive meridians on failure surface for HSG and

17 FRGC, respectively. In these graphs, a comparison has also been made between the failure envelopes 
1 of HSG and FRGC from this study with those proposed by other researchers for high strength concrete 2 and cement based fiber reinforced composites.

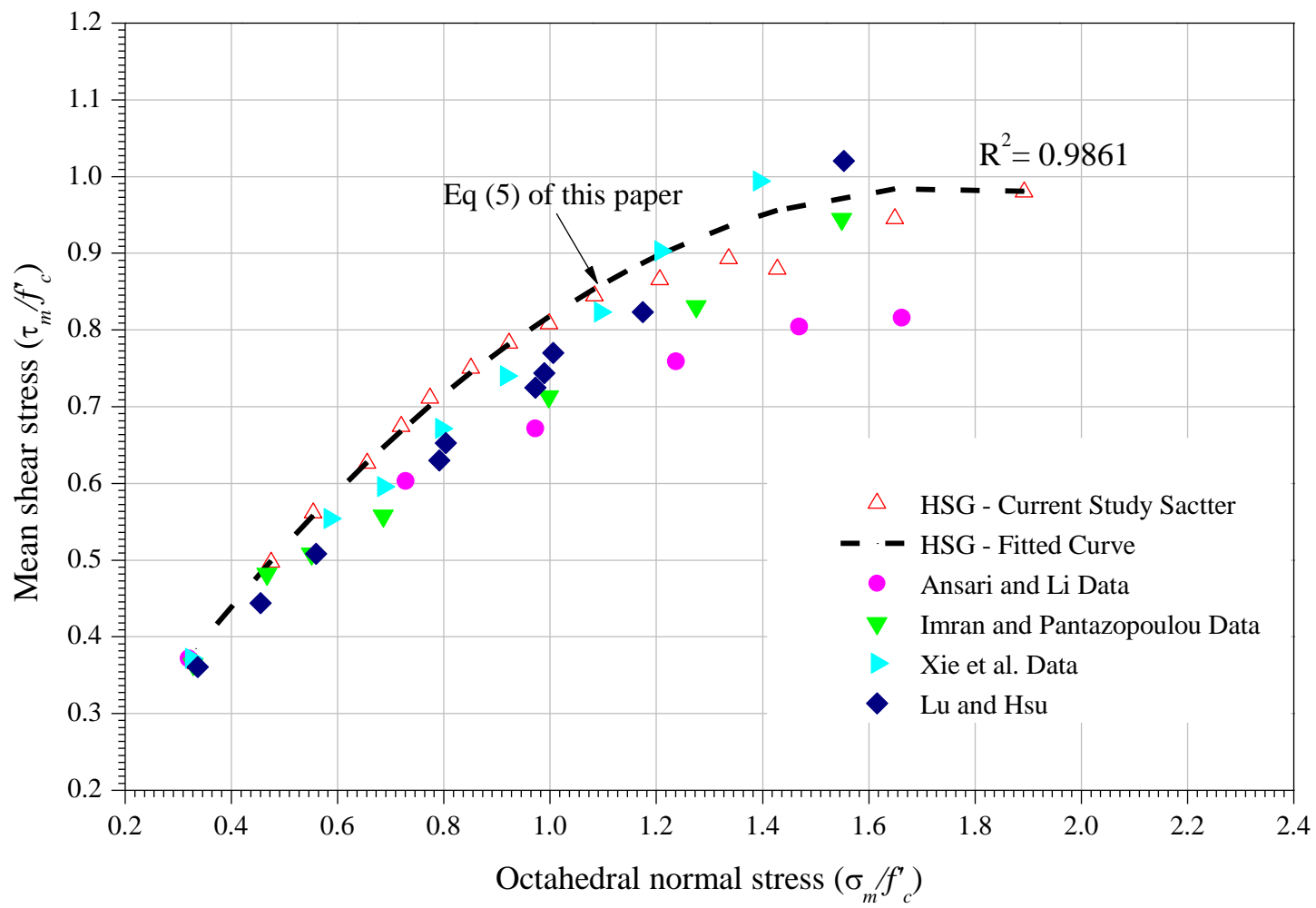

Fig. 10. Comparison of compressive meridian of HSG and HSCs from previous studies

5 As can be seen, the Willam-Warnke failure criterion provides a proper failure envelope for both types of geopolymer materials. Furthermore, in Fig. 10, it can be seen that the geometric shape of

7 compressive meridian proposed by Ansari and $\mathrm{Li}[21]$ is similar to the failure envelope suggested for 8 HSG in this study, where after a certain level of octahedral normal stress, the compressive meridian of 9 HSG tends to reach a plateau. On the other hand, it is evident that among different investigations, Ansari and Li's model produces a lower strength boundary for all lateral confinement ratios, while the test

11 results from other studies are scattered below the defined compressive meridian of HSG defined by Eq.

12 (5) within the considered confining pressure range. 
1 Fig. 11 shows the comparison of the compressive meridian of the FRGC from Eq. 6 of this research 2 and studies of Lu and Hsu [26], Ren et al. [45], and Babanajad et al. [46]. Although the strengths of 3 FRGC samples and cement based fiber reinforced concretes/composites are quite similar, the 4 compressive meridian for FRGC, however, does not fall within the same failure envelope apart from a 5 few data points from this research. Therefore, separate compressive meridians are proposed for the 6 studied materials.

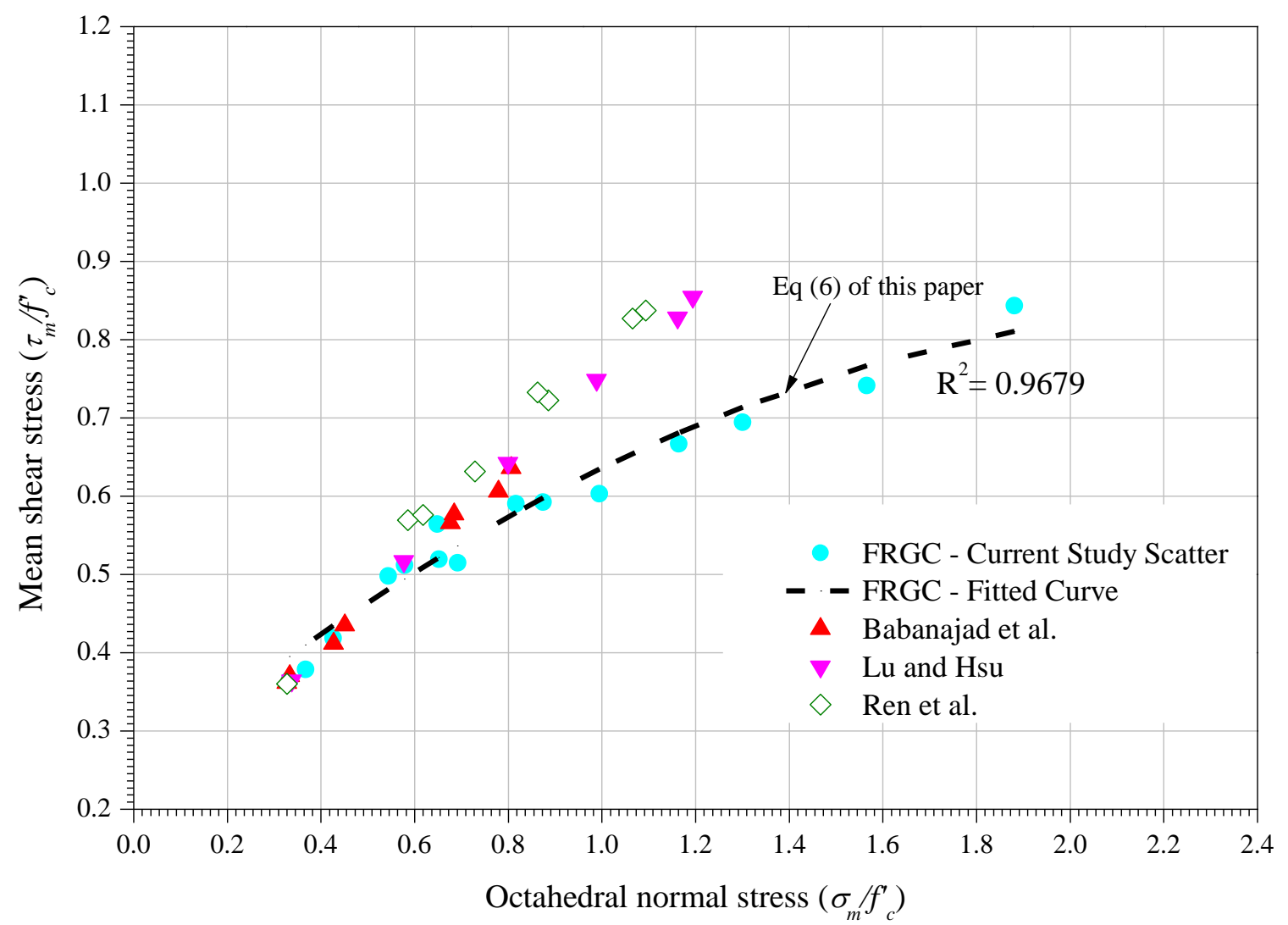


1 identical. Therefore, failure patterns at discerning lateral confinement ratios are presented only.

2 Generally, the unreinforced HSG samples behaved differently under triaxial compression as compared

3 to what was observed in uniaxial stress condition. It can be seen that in the absence of confinement,

4 several major macroscopic tensile cracks were produced parallel to the axial loading direction which

5 triggered the sample failure. In triaxial compression, the failure planes tilted diagonally to reach an

6 inclination of $45^{\circ}$ approximately to the axial direction. These failure planes are typical of shear failure

7 and have frequently been observed for cement-based materials under triaxial compression [21, 43].
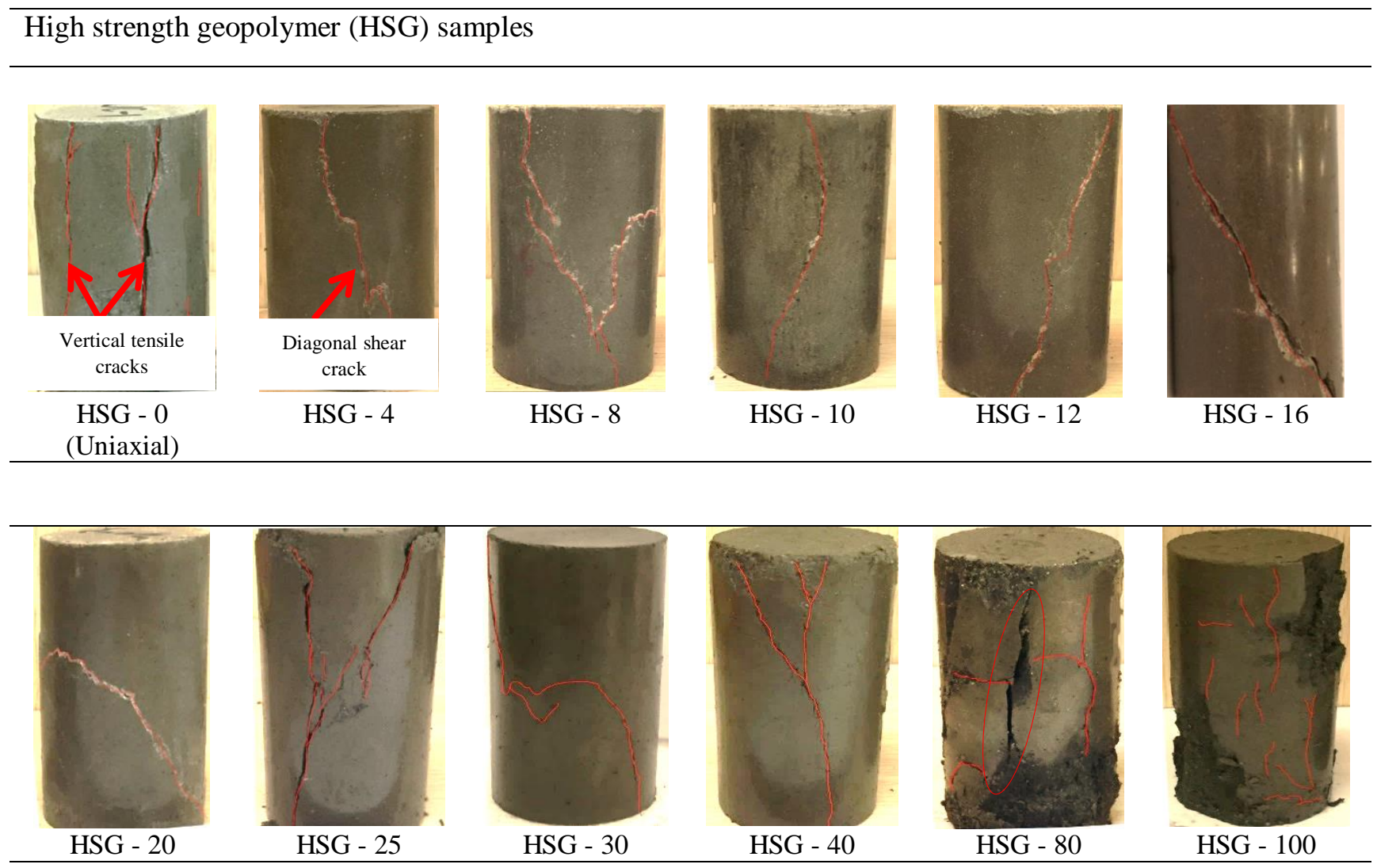

Fiber reinforced geopolymer composites (FRGC) samples 


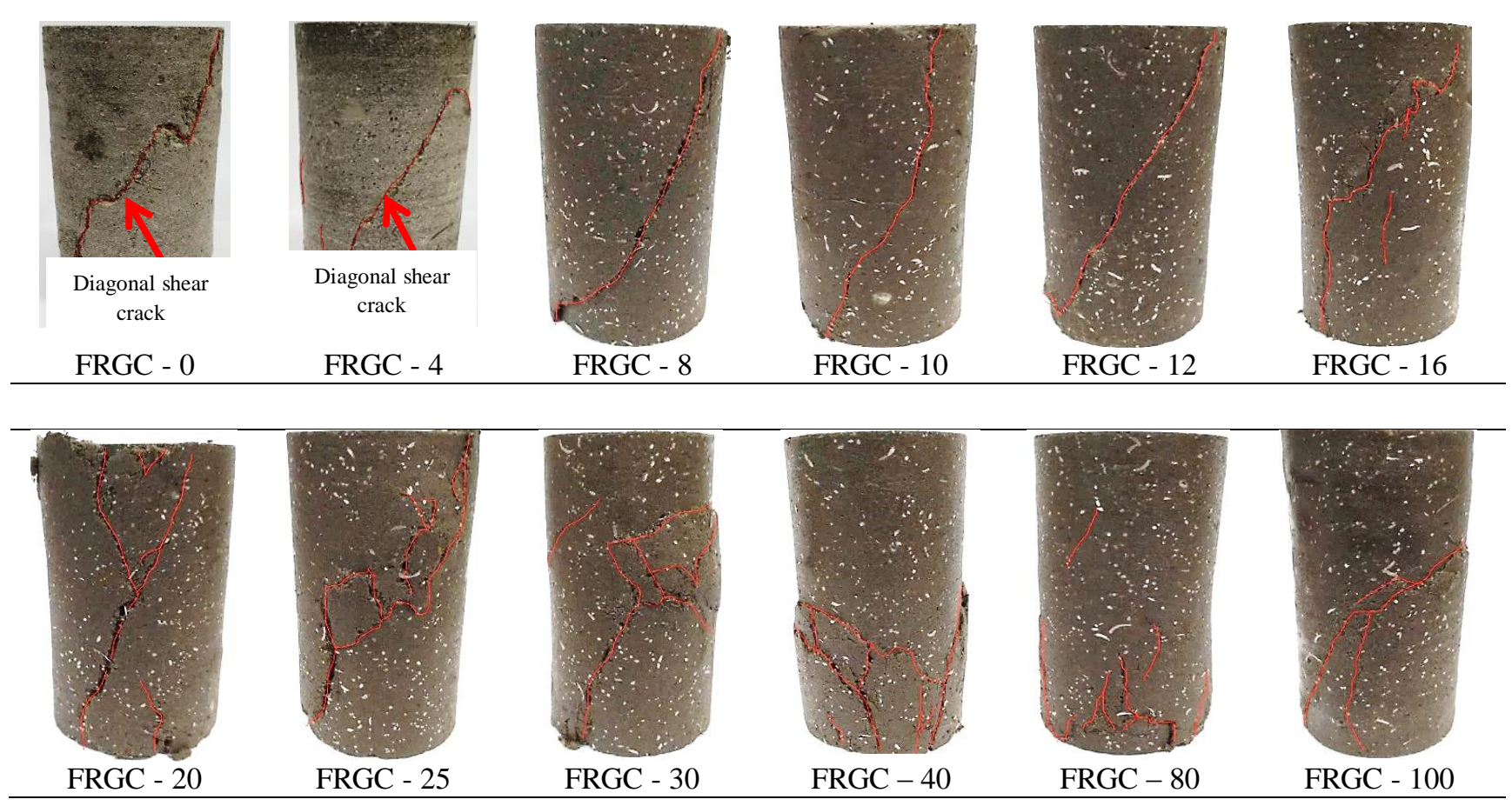

2 Fig. 12. Failure modes of HSG and FRGC in uniaxial and triaxial compressive loading conditions

3 Moreover, it can also be observed that at relatively low or medium confining pressures, the failure in

4 HSG samples was induced either by a single or a set of multiple inclined shear cracks. While at higher

5 confining pressures such as at $80 \mathrm{MPa}$ or $100 \mathrm{MPa}$, not only several major shear cracks were formed

6 but also an extensive amount of abrasion was noticed on top and bottom edges of the tested samples

7 alongside these cracks. A few of the HSG samples subjected to higher levels of confinement (i.e., 80

$8 \mathrm{MPa}$ and $100 \mathrm{MPa}$ ) also broke into several pieces once the protective sleeves were removed after the

9 test completion.

10 On the other hand, from Fig. 12, it can be seen that the FRGC samples maintained their structural

11 integrity to a large extent after enduring the triaxial compression. It can be observed that unlike the

12 unreinforced geopolymer mortar samples, the failure in FRGC samples was induced due to the

13 formation of the inclined shear cracks in uniaxial loading condition. Upon confinement, visible shear 
1 cracks developed which caused the sample failure. However, with an increase in the confining stresses,

2 an apparent swelling of samples was noticed around the circumference mainly due to the axial

3 contractions, and minor hair-line cracks appeared on surfaces of the tested samples. It is different to

4 HSG samples and indicates that the addition of fibers not only improved the failure mode of HSG in

5 uniaxial compression but also allowed the fiber reinforced specimens to retain their integrity at high

6 levels of confining stress states.

\section{4. Conclusions}

8 This paper investigated the influence of lateral confinement on ambient cured high-strength 9 geopolymer mortar and fiber-reinforced geopolymer composites through a comprehensive 10 experimental test program. The material behaviours are studied over a range of confining pressures 11 between 0 and $100 \mathrm{MPa}$. Based on the findings of this experimental study, the following conclusions 12 can be drawn:

(a) Under uniaxial compression, the unreinforced HSG samples showed linear elastic response and experienced a catastrophic brittle failure. But a noticeable improvement in ductility and increased resistance to post-peak deformation was observed with the inclusion of hybrid steelpolyethylene fiber reinforcement.

(b) Under triaxial compression, the axial strength and ductility of HSG and FRGC samples exceeded the corresponding values observed in uniaxial stress states. A concomitant increase in the failure strength and axial strain was seen with an increase in the confining pressures for both types of studied materials.

(c) Obvious nonlinear relationships existed between the peak axial stress and the confining pressure for both HSG and FRGC materials similar to high strength OPC concretes. However, the 
influence of confining pressure was more pronounced on the failure strength of HSG material in comparison with fiber reinforced geopolymer composite specimens.

(d) A distinct effect was noticed on to the compressive meridian of failure surface for HSG at low to medium levels of confinement. At higher confining pressures, the failure curve of HSG tends to reach a plateau. On the other hand, the proposed compressive meridian for FRGC is more linear at higher confinements.

(e) The calibrated Power-law and Willam-Warnke failure criteria provide an excellent fit to the test data. However, the proposed compressive meridian envelope suggest an upper strength boundary for HSG in comparison to the conventional high strength OPC concrete within the considered test range.

(f) The proposed empirical relations can be used to calibrate the strength parameters of existing concrete models and to simulate the behaviour of HSG under active lateral confinements.

(g) The HSG samples failed predominantly due to the formation of vertical tensile cracks in uniaxial compression, while the failure modes transformed to shear under triaxial compressive stress condition. On the other hand, shear failure patterns were observed for FRGC samples both in the uniaxial and triaxial compressive tests.

\section{Acknowledgements}

This research was possible due to the financial support provided by Australian Research Council under grant no DP160104557 and the opening project of State Key Laboratory of Explosion Science and Technology (Beijing Institute of Technology) under grant no. KFJJ17-07M. The authors are extremely grateful to the laboratory staff at Central South University, China for their assistance in execution of the tests. The first author would also like to gratefully acknowledge the scholarship from National University of Sciences \& Technology, Pakistan and Curtin University, Australia to carry out his Ph.D. study. 


\section{References}

1. Davidovits J. High alkali cements for 21 st century concretes, concrete technology, past, present, and future. In: Mehta PK, editor. American Concrete Institute; 1994. p. 383-97.

2. Sakulich, Aaron Richard. (2011). Reinforced geopolymer composites for enhanced material greenness and durability. Sustainable Cities and Society, 1 (4):195-210.

3. Atiş CD, Görür EB, Karahan O, Bilim C, İlkentapar S, Luga E. Very high strength (120 MPa) class F fly ash geopolymer mortar activated at different $\mathrm{NaOH}$ amount, heat curing temperature and heat curing duration. Construction and Building Materials. 2015;96:673-8.

4. Hosan A, Haque S, Shaikh F. Compressive behaviour of sodium and potassium activators synthetized fly ash geopolymer at elevated temperatures: A comparative study. Journal of Building Engineering. 2016;8:123-30.

5. Benhalal, E, Zahedi, G, Shamsaei, E., and Bahodori, A., (2012). Global strategies and potentials to curb $\mathrm{CO}_{2}$ emissions in cement industry. Journal of Cleaner Production, 51(0): 142-161.

6. Khan MZN, Shaikh FuA, Hao Y, Hao H. Synthesis of high strength ambient cured geopolymer composite by using low calcium fly ash. Construction and Building Materials. 2016;125:809-20.

7. Rashad, Alaa M. 2014. A comprehensive overview about the influence of different admixtures and additives on the properties of alkali-activated fly ash. Materials \& Design 53 (0):1005-1025

8. Part, Wei Ken, Mahyuddin Ramli, and Chee Ban Cheah. 2015. An overview on the influence of various factors on the properties of geopolymer concrete derived from industrial by-products. Construction and Building Materials 77:370-395.

9. Khan MZN, Shaikh FUA, Hao Y, Hao H. Effects of Curing Conditions and Sand-to-Binder Ratios on Compressive Strength Development of Fly Ash Geopolymer. Journal of Materials in Civil Engineering. 2017;30(2):04017267.

10. Roviello G, Menna C, Tarallo O, Ricciotti L, Ferone C, Colangelo F, et al. Preparation, structure and properties of hybrid materials based on geopolymers and polysiloxanes. Materials \& Design. 2015;87:82-94.

11. Shaikh, Faiz Uddin Ahmed. 2013. Review of mechanical properties of short fiber reinforced geopolymer composites. Construction and Building Materials 43 (0):37-49.

12. He Z-j, Song Y-p. Triaxial strength and failure criterion of plain high-strength and high-performance concrete before and after high temperatures. Cement and Concrete Research. 2010;40(1):171-8.

13. Chen WF. Concrete plasticity: Macro- and microapproaches. International Journal of Mechanical Sciences. 1993;35(12):1097-109.

14. Richart, F.E, Brantzaeg, A., and Brown, R. L. The failure of plain and spirally reinforced columns in compression. University of Illinois Engineering Experimental Station, Bulletin No. 190, 1929.

15. Cusson D, Paultre P. Stress-strain model for confined high-strength concrete. Journal of Structural Engineering. 1995;121(3):468-77.

16. Monterrey P, Willam K. Triaxial failure criterion for concrete and its generalization. Structural Journal. 1995;92(3):311-8.

17. Candappa D, Sanjayan J, Setunge S. Complete triaxial stress-strain curves of high-strength concrete. Journal of Materials in Civil Engineering. 2001;13(3):209-15.

18. Ottosen NS. Constitutive model for short-time loading of concrete. Journal of the Engineering Mechanics Division ASCE. 1979;105:127-41.

19. Xie J, Elwi A, MacGregor J. Mechanical properties of three high-strength concretes containing silica fume. Materials Journal. 1995;92(2):135-45.

20. Imran I, Pantazopoulou S. Experimental study of plain concrete under triaxial stress. ACI Materials Journal-American Concrete Institute. 1996;93(6):589-601.

21. Ansari F, Li Q. High-strength concrete subjected to triaxial compression. Materials Journal. 1998;95(6):747-55.

22. Samani AK, Attard MM. A stress-strain model for uniaxial and confined concrete under compression. Engineering Structures. 2012;41(Supplement C):335-49. 
23. Haider GM, Sanjayan JG, Ranjith PG. Complete triaxial stress-strain curves for geopolymer. Construction and Building Materials. 2014;69(0):196-202.

24. Xiao Q, Teng J, Yu T. Behaviour and modeling of confined high-strength concrete. Journal of Composites for Construction. 2010;14(3):249-59.

25. Farnam Y, Moosavi M, Shekarchi M, Babanajad SK, Bagherzadeh A. Behaviour of Slurry Infiltrated Fiber Concrete (SIFCON) under triaxial compression. Cement and Concrete Research. 2010;40(11):1571-81.

26. Lu X, Hsu C-TT. Behaviour of high strength concrete with and without steel fiber reinforcement in triaxial compression. Cement and Concrete Research. 2006;36(9):1679-85.

27. Lyu S-J, Hsiao Y-H, Wang T-T, Cheng T-W, Ueng T-H. Microstructure of geopolymer accounting for associated mechanical characteristics under various stress states. Cement and Concrete Research. 2013;54:199-207.

28. Nasvi MCM, Ranjith PG, Sanjayan J. A numerical study of triaxial mechanical behaviour of geopolymer at different curing temperatures: An application for geological sequestration wells. Journal of Natural Gas Science and Engineering. 2015;26:1148-60.

29. Khan MZN, Hao Y, Hao H, Shaikh FUA. Mechanical properties of ambient cured high strength hybrid steel and synthetic fibers reinforced geopolymer composites. Cement and Concrete Composites. 2018;85(Supplement C):133-52.

30. Khan MZN, Hao Y, Hao H, Shaikh FUA. Experimental evaluation of quasi-static and dynamic compressive properties of ambient-cured high-strength plain and fiber reinforced geopolymer composites. Construction and Building Materials. 2018;166:482-99.

31. ASTM C618-12a. Standard specification for coal fly ash and raw or calcined natural pozzolan for use in concrete. West Conshohocken, PA.

32. ASTM C128-15. Standard test method for relative density (specific gravity) and absorption of fine aggregate. West Conshohocken, PA.

33. ASTM C1437-13. Standard test method for flow of hydraulic cement mortar. West Conshohocken, PA.

34. Vu XH, Malecot Y, Daudeville L, Buzaud E. Experimental analysis of concrete behaviour under high confinement: Effect of the saturation ratio. International Journal of Solids and Structures. 2009;46(5):1105-20.

35. Bazant ZP, Tsubaki T. Total strain theory and path-dependence of concrete. Journal of the Engineering Mechanics Division, ASCE, Volume 106, no. EM6, Dec. 1981, pp. 1151-1172.

36. Attard M, Setunge S. Stress-strain relationship of confined and unconfined concrete. Materials Journal. 1996;93(5):432-42.

37. Mander J, Priestley M, Park R. Observed stress-strain behaviour of confined concrete. Journal of structural engineering. 1988;114(8):1827-49.

38. Davidovits J. Geopolymers. Journal of thermal analysis. 1991;37(8):1633-56.

39. Duxson P, Provis JL, Lukey GC, Mallicoat SW, Kriven WM, van Deventer JSJ. Understanding the relationship between geopolymer composition, microstructure and mechanical properties. Colloids and Surfaces A: Physicochemical and Engineering Aspects. 2005;269(1-3):47-58.

40. Hardjito, D. and Rangan, B. V. Development and Properties of low calcium fly ash based geopolymer concrete. Research Report GC 1, Curtin University of Technology, Perth, Australia, 200593 pp.

41. Pantazopoulou S, Zanganeh M. Triaxial tests of fiber-reinforced concrete. Journal of Materials in Civil Engineering. 2001;13(5):340-8.

42. Ahmed SFU, Ronnie Z. Ductile behaviour of polyethylene fiber reinforced geopolymer composite. MATEC Web of Conferences: EDP Sciences; 2017. p. 01047.

43. Noori A, Shekarchi M, Moradian M, Moosavi M. Behaviour of Steel Fiber-Reinforced Cementitious Mortar and High-Performance Concrete in Triaxial Loading. ACI Materials Journal. 2015;112(1).

44. Chen W-F. Plasticity in reinforced concrete: J. Ross Publishing; 2007.

45. Ren GM, Wu H, Fang Q, Liu JZ, Gong ZM. Triaxial compressive behaviour of UHPCC and applications in the projectile impact analyses. Construction and Building Materials. 2016;113(Supplement C):1-14. 
46. Babanajad SK, Farnam Y, Shekarchi M. Failure criteria and triaxial behaviour of HPFRC containing high reactivity metakaolin and silica fume. Construction and Building Materials. 2012;29:215-29.G 